\title{
Climate Change and Migration: Is Agriculture the Main Channel?
}

\author{
Chiara Falco \\ Department of Environmental Science and Policy, \\ University of Milan \\ Marzio Galeotti \\ Department of Environmental Science and Policy, \\ University of Milan and GREEN-Bocconi University \\ Alessandro Olper* \\ Department of Environmental Science and Policy, \\ University of Milan and LICOS - Centre for Institution and \\ Economic Performance, KU Leuven
}

\begin{abstract}
Migration and climate change are two of the most important challenges the world currently faces. They are connected as climate change may stimulate or hinder migration. One of the sectors strongly affected by climate change is agriculture, which is the source of income for most of the world's poor. Climate change may affect agricultural productivity and hence migration because of its impact on average temperatures and rainfall and because it increases the frequency and intensity of weather shocks. In this paper we use data on 108 countries from 1960 to 2010 to analyze the relationship between weather variations, changes in agricultural productivity and international migration. We find that negative shocks to agricultural productivity caused by climate fluctuations significantly increase emigration from developing countries, an especially strong impact in poor countries but less so in middle income countries. These results are robust to the definitions of the poor country sample, and to several checks and alternative explanations suggested by the literature. Importantly, our results point to a causal interpretation of the agricultural channel to explain the climate changemigration nexus.
\end{abstract}

JEL classifications: F22, Q54, 013, Q15

Keywords: Climate change, Temperature, Agriculture, International Migration

*Corresponding author. E-mail address: alessandro.olper@unimi.it

Final version of the manuscript accepted by the Editor and published on Global Environmental Change (Issue 59, 2019). https://doi.org/10.1016/i.gloenvcha.2019.101995 


\section{Introduction}

In recent years, the empirical literature on the relationship between migration and climatic change has been growing rapidly and environmental factors are increasingly recognized as an important driver of both internal and cross-border migration (Berlemann and Steinhardt, 2017). However, no clear consensus on the adverse impact of environmental conditions - such as natural disasters and extreme weather as well as more gradual climate change - on migration has yet been reached (Mastrorillo et a. 2016). This is not surprising, given the heterogeneity of the empirical literature in terms of data used and approaches adopted that span multiple disciplines with wide-ranging methodologies and limited theoretical development (Hunter et al. 2016). In addition, migration is a complex phenomenon driven by a plurality of economic, social, demographic and historical factors, where climate change and natural disasters could, eventually, represent just one among many aspects (Black et al. 2011; Adger et al. 2014).

However, within the recent macroeconomic literature on climate change and international migration the impact of the increasing average surface temperature on agricultural productivity has been suggested as a potential key factor of the decision to migrate (Cai et al., 2016; Cattaneo and Peri, 2016). This is because, on the one hand, agriculture is the main source of income and employment in the rural areas of developing countries, where the majority of migrants is coming from. On the other hand, agriculture is the sector mostly affected by climate change with important implications for agricultural productivity, rural livelihoods and food security, especially in the developing world (Lobell et al., 2011; FAO, 2017).

History provides several illustrative examples of negative climatic shocks inducing people to migrate, with agriculture apparently playing a key role. For example, one of the most studied climate and migration events is the so-called "American Dust Bowl", the large dust storms that affected many U.S. and Canadian counties in the 1930s. As shown by Hornbeck (2012), the 
permanent soil erosion and the agricultural costs induced by these storms have been partially mitigated by both short- and long-run out-migration from the most to the less affected counties. Similarly, how climate triggered migration from southwest Germany to U.S. during the 19th century has been recently documented by Glaser et al. (2017). These authors argue that the effect of cold weather on high grain prices appears to be central to German migration, showing considerable influence of weather conditions on harvests, and consequently on out-migration.

Starting from the seminal work of Todaro (1969) and Harris and Todaro (1970), economists have interpreted migration as resulting from differences in economic opportunities or, more precisely, from expected wage differentials between origin and destination countries. In addition, migration is considered a way to diversify income sources (Rosenzweig and Stark, 1989), a way to deal with bad political institutions and conflicts (Naudé, 2010; Dell et al. 2012), and, finally, a possible insurance mechanism against environmental shocks (McLeman and Smit, 2006; Drabo and Mbaye, 2015).

The current literature investigating how weather variability and climatic shocks may affect migration has been mostly using individual data and household surveys (e.g. Dillon et al., 2011; Mueller et al., 2014; Gray and Mueller, 2012; Gray and Bilsborrow, 2013; Bohra-Mishra et al., 2014). The main findings show that, though climatic shocks often trigger both internal and international migration, the relationship appears to be a complex one and the effects are often country-specific (Gray and Wise, 2016). In addition, several conflicting results have emerged, such as the apparently low or no effect of both sudden climatic shocks (i.e. natural disasters) and precipitations, relative to the apparent strong impact of temperature (Mueller et al., 2014; Bohra-Mishra et al., 2014), or reverse effects, namely situations where adverse climate factors may reduce (and not increase) emigration flows (Gray and Mueller, 2012). Yet, within this micro literature a constant theme emphasized by several papers is the role played by the agricultural sector as the mediating channel through which climatic factors result in internal and international migration (see Berlemann and Steinhardt, 2017). This is not surprising, as the large part of this empirical research comes from countries at a relatively low level of development, located either in Africa, South America, and South Asia, all regions where the agricultural sector, besides being relevant from an economic point of view, is already affected by climatic shocks (Adger et al. 2014). 
One critical issue of this emerging literature is the few macro studies focusing on climate change and international migration, making the generalization of the current (micro) evidence problematic. Important developments in data collection, such as the bilateral migration dataset of Özden et al. (2011), have recently triggered a new wave of (macro) studies on the impact of climate change on international migration (e.g. Beine and Parsons, 2015; Cattaneo and Peri, 2016; Maurel and Tuccio, 2016; Cai et al., 2016; Groschl and Steinwachs, 2017). They have confirmed some of the previous micro evidence, but also have raised new issues. In particular, when the focus is on the mechanisms driving the results, the current empirical evidence is at best scant. This is an important limitation of the literature, especially because there is evidence suggesting that the effect of climate change on international migration, if anything, tends to be mainly indirect and mediated by other socio-economic characteristics (Black et al., 2011; Beine and Parsons, 2015; Kubik and Maurel, 2016). Clearly, understanding the extent to which some key mechanism and channel tend to be those that are key for the climate-lead migration is crucial in view of the formulation of evidence-based policy recommendations (Mbaye, 2017).

Using different approaches and different datasets, a few recent papers explicitly investigate the relationship between climate change and international migration emphasizing the role of the agricultural channel (see Feng et al., 2010; Cattaneo and Peri, 2016; Cai et al., 2016). However, with the exception of Feng et al. (2010), who implement a more structural approach based on casual inference to study the link between climate-driven changes in crop yields and migration between Mexico and the U.S., the current available evidence is more based on robust association than a careful identification of the true mechanism in place. Thus, the presumption that agriculture is one of the key mediating channels in the climate change and migration relationship, is still an open and unresolved empirical question.

Against this background, the present paper uses a macro perspective to study the extent to which the effect of weather shocks on migration works mainly through the agricultural channel. We contribute to the existing literature in several respects. First, we exploit a large data set of 108 countries observed from 1960 to 2010 to investigate the extent to which longrun climate-driven changes in agriculture productivity affect migration. Second, and more importantly, we use an approach based on a two-stage least square (2SLS) research design to test if there exists a causal relationship between changes in agricultural conditions driven by 
climatic shocks and migration outcomes. From this perspective, our research design is similar to Feng et al. (2010), but contrary to them, we systematically control for other important determinants of migration and unobserved time shocks, a critical difference that significantly improves the credibility of our findings (see Auffhammer and Vincent, 2012). Thirdly, we carry out our analysis by investigating the above effects separately for poor and middle-income countries, so as, to assess whether there are statistically significant differences among the two groups. This is important because some recent findings showed that in poor countries climate shocks do not systematically induce migration, a result that might be due to liquidity constraints (see Cattaneo and Peri, 2016). Finally, the same 2SLS approach is applied also to study the role of most often mentioned alternative hypotheses other than the agricultural channel, such as overall income effects, conflicts, political instability and health issues. This is an important test to rule out the possibility that our agricultural variables are indeed picking up the effect of these alternative channels.

Overall, our results provide convincing support to the idea that negative shocks to agricultural productivity caused by (long-run) weather variation, on average, positively affect net migration outflows. Importantly, this climate-driven agricultural shocks affect mainly migration from poor countries, and less so from middle-income countries.

The remainder of the paper is organized as follows. Section 2 briefly considers the related literature, while Section 3 provides some conceptual background underlying the econometric specification. Section 4 illustrates the empirical methodology used to identify the agricultural channel and Section 5 describes the data used for the empirical analysis together with some descriptive statistics. Section 6 presents the main results while robustness checks are reported in Section 7. Section 8 concludes.

\section{Related Literature}

The present paper relates to two strands of the recent, burgeoning literature on the impacts of climate on socio-economic outcomes (see the reviews by Dell et al., 2014, and by Carleton and Hsiang, 2016). The first one is given by the stream of papers, which investigate the effects of weather and climate change on agricultural (and overall) productivity (Mendelsohn et al., 
1994; Schlenker et al., 2006; Deschenes and Greenstone, 2007; Lobell et al., 2011; Dell et al., 2012; Auffhammer and Schlenker, 2014; Burke et al., 2015b; Hsiang, 2016). The second area looks at direct and indirect effects of climate change on international migration (Feng et al., 2010; Marchiori et al., 2012; Beine and Parsons, 2015; Cattaneo and Peri, 2016; Cai et al., 2016; Maurel and Tuccio, 2016; Berlemann and Steinhardt, 2017).

Within the first strand of literature, the seminal paper of Mendelsohn et al. (1994) used a crosssectional hedonic model to study the relationship between farmland price across U.S. counties and growing season temperature and precipitations. The main finding was that a higher temperature significantly reduces land value, while higher precipitations tend to increase it; on the whole global warming had a very low impact on U.S. agriculture. Using a similar crosssectional approach, Schlenker et al. (2006) reached the quite different conclusion that the aggregate impact of warming for the U.S. counties considered in the near to medium term is a $10 \%-25 \%$ decrease in aggregate land value.

Unlike the previous contributions, Deschenes and Greenstone (2007) exploit the within time variation to identify whether agricultural profits in U.S. counties respond to random fluctuations in weather. The main finding is that climate change only marginally affects agricultural profits. Importantly, they also demonstrate how the hedonic approach based on cross-sectional inference, i.e. the standard approach followed until then, is unreliable due to sever problems of omitted variables bias.

Since the contribution of Deschenes and Greenstone (2007) the use of panel data models has become the standard approach within the climate econometric literature. For example, Schlenker and Roberts (2009) uncover important non-linear effects of temperature on U.S. crop yields that exacerbate the predicted decrease in yield due to global warming. Lobell et al. (2011) investigate the effect of weather trends on the main crops production, showing that global warming has been responsible for a decline in global corn and wheat production of about $3.8 \%$ and $5.5 \%$, respectively. Dell et al. (2012) study the weather effects on both level and growth rate of per capita GDP. The results highlight a negative effect of an increase in temperatures on per capita GDP growth for poor countries: a $1^{\circ} \mathrm{C}$ increase in temperature in a given year reduces poor countries' economic growth by $1.3 \%$, an effect driven mainly by a 
reduction in agricultural output, and less by industrial output and political instability. However, as recently showed by Newell et al. (2018), the idea that temperature affects mainly economic growth instead of the level of GDP is not yet well understand by the current literature. Yet, the distinction is relevant because growth effects cumulate over time, while level effects have mainly transitory effects, thus implying different long-run impacts of global warming. In the case of agriculture, the literature on the impacts of temperature on yields and productivity highlights mainly level effects (see, e.g., Lobell et al, 2011; Olper et al, 2019).

As discussed in detail by Dell et al. (2014), the key advantage of a panel data identification strategy is that it accounts for unobservable differences between units through fixed effects, thus eliminating a potential source of omitted variables bias. An additional advantage is the time variation in weather variables which, after accounting for fixed effects, is exogenous with respect to changes in socio-economic variables because it is driven by random geophysical processes. However, a drawback of using panel methods with inter-annual variation of weather is the inability of fully capturing adaptation to climate changes.

With the aim of addressing this critical issue, some papers have recently proposed a long differences approach (Dell et al., 2012; Burke and Emerick, 2016). The idea is that, because changes in climate are gradual, averaging across long time spans (e.g. a decade) should offer the possibility of capturing both direct and belief effects (i.e. adaptation) of climate change. This is because populations only adjust their beliefs when environmental changes are expected to be persistent (Hsiang, 2016). However, studies that compared the weather effect using data at both short- and long-run frequency have found that the magnitude of the estimated effects of climate change on agricultural yields (and other economic variables) are not so different (Dell et al., 2012; Burke and Emerick, 2016), thus suggesting a quite limited historical adaptation to climate change.

The decision to migrate internationally is often viewed as a long-run adaptation strategy intended to cope with the direct (and indirect) effects of permanent, not transitory, weather changes. In this respect the idea that people may decide to migrate internationally as a response to (just) yearly variation in weather is admittedly not without problems (Jessoe et al., 2018). For this reason, in the present paper we identify the effects of weather-driven 
agricultural changes on migration using long-run (decennial) variations in the variables of interest, a choice also dictated by data limitation. As noted by Burke and Emerick (2016), this approach offers advantages over short-run panel methods, because it better approximates the ideal experiment, addresses potential omitted (time-invariant) variable bias and, at the same time, should capture medium-run adaptations that farmers put in place against trends in weather, such as migration. Moreover, as argued by Dell et al. (2014), intensification effects should also be captured, namely situations when climate change may cause damages that are not revealed by small weather changes, but that can be relevant in agriculture. An example are situations where the permanent reduction of precipitations strongly affects the reservoir availability of water for agriculture.

The above considerations notwithstanding, it is to be noted that there are also drawbacks in using data with low frequency. For example, several papers suggest that temporary migration could be a coping strategy against adverse weather conditions, and this holds also for international movements (see, e.g., Marchiori et al., 2012). More generally, while highfrequency data miss those migration movements that take place over a longer time span, lowfrequency data are likely to miss (or poorly identify) part of those movements. Hence, these two approaches should be considered as complements rather than substitutes. In addition, one potential limitation of using decennial data variation is the identification of climatic variables, because averaging temperatures and precipitations over long time spans might reduce the ability to identify important climatic changes that could significantly impact agricultural output and productivity (Coniglio and Pesce, 2015). Not surprisingly, studies using high-frequency data tend to find more often statistically significant impacts of climate variables on migration patterns (see Beine and Jeusette, 2018).

Turning to the literature on migration and climate change with special attention to the role of agriculture, Marchiori et al. (2012) study the impact of weather anomalies on migration in subSaharan Africa. Assuming that agriculture, and hence rural areas, is most vulnerable to weather changes, the authors argue that the more a country depends on agriculture, the stronger is the impact of weather anomalies on migration. Using an instrumental variable (IV) approach for GDP per capita, it is found that climate anomalies spur both internal and international migration and that urbanization might mitigate the effects of climatic factors on international 
migration, mainly in rural areas. Beine and Parsons (2015) investigate natural disasters and long-run climatic factors (temperature and precipitations) as potential determinants of international migration. Using a gravity-like approach they find that by affecting wage differentials long-run climatic factors have only indirect effects on bilateral migration. In addition, some of their results depend upon a country's agriculture share of GDP (similar results can also be found in Maurel and Tuccio, 2016, and in Drabo and Mbaye, 2015).

Following the same macroeconomic approach, Coniglio and Pesce (2015) explicitly consider the heterogeneity of climatic shocks (type, size, sign of shocks and seasonal effects) paying specific attention to the role of expectations. Given the dataset used, the authors can only account for emigrants to OECD countries, which importantly limits the scope of their analysis given that a huge number of migrants in fact displace in neighboring developing countries. Nevertheless, the results are in line with other studies according to which the occurrence of adverse climatic events in the origin country has significant direct and indirect effects on outmigration from poor to rich countries, especially from areas with large agricultural sectors.

Using decennial data for 115 countries between 1960 and 2000, Cattaneo and Peri (2016) extend the model of migration of Borjas (1985) where the key assumption is that income in poor and middle income countries, being largely dependent on the agricultural sector, is more affected by weather variability. Accordingly, they find a positive impact of warming trends on the probability to emigrate in middle-income countries, whereas in poor countries a negative relationship emerges that is attributed to liquidity constraints.

Two additional studies are directly relevant for the work we carry out in this paper. Feng et al. (2010) adopt a 2SLS estimation strategy using weather variables to instrument agricultural productivity to investigate the extent to which climate-driven yield changes have a causal effect on emigration. Exploiting migration data from Mexico to the U.S. in two consecutive five-year periods (1995-2000 and 2000-2005), they find that a 10\% decrease in yields causes an additional 2\% of population to emigrate. However, Auffhammer and Vincent (2012) note that Feng et al. (2010) do not account for time fixed effects in their specification and show that this omission implies that the climate-induced emigration effects cannot be distinguished from other simultaneous shocks occurred in the same period, such as NAFTA, the Peso crisis, and 
changes in U.S. border controls after 2001. Thus, these factors, and not climate change, were responsible for the change in emigration rates. Cai et al. (2016) use bilateral annual data over the period 1980-2010 covering 163 origin and 42 destination countries (mainly OECD) and use cereal yields and the share of agricultural value added in GDP to account for the role of agriculture in explaining international migration, controlling for country pair fixed effects. Their main finding is that temperature (but not precipitations) has a positive and statistically significant effect on international migration outflows only for agriculture-dependent countries. However, besides the use of bilateral migration data, the role of the agricultural channel is still identified indirectly, and not through a structural model that allows to quantify the migration elasticity to agricultural income shocks.

The review of the current literature undertaken above suggests that there is scope for further analysis. On the one hand, papers using a more structural approach based on 2SLS methods such as Feng et al. (2010) produce results apparently not robust to potential (omitted) confounding factors. On the other hand, the reduced-form approach used by Cai et al. (2016) and Cattaneo and Peri (2016), though robust from an econometric point of view, is able to confirm only the existence of an indirect association between climate change, the importance of agriculture and migration. Thus, whether weather-driven changes in agricultural productivity have a causal effect on international migration is still an unanswered question. This is what motivates the present paper. Specifically, our aim is to investigate the extent to which the agricultural channel, i.e. climate-driven shocks to agricultural income, represents an important mechanism through which climate change induces people to migrate.

\section{Theoretical considerations}

As a motivation for the subsequent empirical analysis, we provide some conceptual background on the determinants of the migration decision. To this end it is useful to start from the model by Cattaneo and Peri (2016), also in view of the apparent consistency of its predictions with some existing evidence. We focus on this specific migration model because it is simple and intuitive and because it is one of the few that explicitly allows for the role of agriculture in the analysis of the climate-migration nexus. Of course, there are other models where agriculture plays a role 
but are more complex (see, e.g., Marchiori et al. 2012).

This two-period model builds on the framework originally proposed by Roy (1951) and later formalized by Borjas (1987), according to which an individual will migrate if his expected wage at destination is higher than the expected wage at origin at a given time. The key assumption of the model is that the wage at origin and at destination is a basic income which may vary with, on the one hand, the importance of agricultural and non-agricultural sectors within the country and, on the other hand, a skill measure which accounts for the migrants selection process (see Stark and Bloom, 1985; Docquier and Rapoport, 2012).

In the first period the individual earns a specific local wage according to his skills, while in the second period he may choose to migrate as a consequence of a comparison between his wage at origin and his potential wage at destination. The crucial assumption of the model is that, in the origin country the individual will earn an income stream (wage), which depends on weather variables, such as variations in temperature and precipitations. However, the wage at destination is assumed not to depend (or depend less) on weather. This is due to the fact that climatic and weather factors are assumed to affect basic income, which is derived from agriculture, the main source of income in poor and middle-poor countries. These countries are taken to be the sending countries in Cattaneo and Peri (2016)'s framework. On the contrary, income in rich countries does not depend exclusively on the agricultural sector, so that variations in temperature and precipitations could have a different impact.

In the logic of the model an individual will migrate if the expected wage at destination is higher than the expected wage at origin net of migration costs, on the assumption that return to skills are perfectly transferable from origin to destination countries. Taking into account the selection process according to which only a portion of individuals at origin can migrate, and the fact that poor individuals may eventually face liquidity constraints, Cattaneo and Peri (2016) put forth two main propositions: (i) an increase in average temperature is associated with an increase in the emigration rate in the case of middle-income countries; (ii) for poor countries an increase in average temperature is associated with a decrease in the emigration rate due to liquidity constraints. The authors find support to their model's predictions, showing that emigration is negatively (resp. positively) related to temperature in poor countries (measured 
by the last quartile of the income distribution) (resp. middle income countries). The basic econometric specification they adopt is a reduced-form equation where emigration (from both poor and middle-income countries) depends on temperature and precipitations; these weather variables are also interacted with a dummy variable for poor countries, which is found to be statistically significant.

Although these findings provide a logical interpretation to previously conflicting evidence concerning the impact of climate and weather on migration, there remains a number of potentially relevant aspects that need to be further investigated. Firstly, it is important to note that the evidence is based on reduced-form equations, and not on a more structural model where the causal impact through the agricultural channel can be clearly identified. Secondly, it is preferable to conduct the empirical analysis on the basis of separate samples for poor and middle-income countries, especially in consideration of the quite different importance of the agricultural sector for the economy. Thirdly, the role of non-linear effects of weather on agricultural productivity, and thus indirectly on emigration, has to be given greater attention, especially in light of the burgeoning recent literature on weather impacts on economic outcomes (see Burke at al., 2015b; Newell et al. 2018). For example, Cai et al. (2016) find that an increase in temperature positively affects emigration in agriculture-dependent countries in a non-linear fashion. According to these authors, this non-linearity in the (reduced form) migration-temperature relationship should represent a "pre-condition" in support of the agricultural channel because temperature has a strong non-linear impact on yields and agricultural productivity (see Schlenker and Roberts, 2009; Burke et al., 2015b). By contrast, Cattaneo and Peri (2016) do not find empirical support for non-linear weather effects on migration, though they investigate this aspect in their reduced-form migration-weather relationship, with no specific impact through agriculture, and considering the overall sample of both poor and middle-income countries, without distinction.

Accordingly, with the aim to better discriminate between concurrent hypotheses, in what follow we pay specific attention to the (supposed) non-linearity of the climate-agriculturalmigration nexus, using also different (and separate) country samples to highlight the extent to which the agricultural channel works better in poor vs middle income countries. 


\section{Econometric approach}

The standard approach to empirically study the relationship between migration and weather consists of estimating the following equation:

$$
m_{i t}=\boldsymbol{W}_{i t}^{\prime} \boldsymbol{b}+\boldsymbol{Z}_{i t}^{\prime} \boldsymbol{d}+f_{t}+c_{i}+u_{i t}
$$

where the $(\log )$ of the emigration rate, $m_{i t}$ from country $i(i=1, \ldots, N)$ to the world at time $t(t=$ $1, \ldots, T$ ) is regressed on a set of weather shocks, $\boldsymbol{W}_{i t}^{\prime}$, and (possibly) of control variables, $\boldsymbol{Z}_{i t}^{\prime}$. The equation includes a full set of year, $f_{t}$, and of country, $c_{i}$, fixed effects. Finally, $u_{i t}$ is the usual error term.

To account for a differential impact of weather factors on poor countries or for the role of the agricultural sector in certain countries, the weather variables are typically interacted with a dummy variable taking on the value of unity for either poor or agriculture-dependent countries (see Cattaneo and Peri, 2016; Cai at al., 2016). Note that $\boldsymbol{W}_{i t}^{\prime}$ may contain terms, such as average temperature squared, to allow for non-linear effects of weather on emigration.

The representation in (1) is usually referred to as the reduced-form relationship between migration and weather, in that it obscures the channels and mechanisms through which temperature and other weather variables may affect migration flows. As argued in the previous sections, a prominent role is played by agriculture especially in those countries where the sector is a relevant source of basic income. Figure 1 highlights these aspects. In particular, the reduced-form relationship between migration and weather is illustrated by the green arrow, whereas the role of agriculture is shown to lie between climate (blue arrow) and migration (red arrow).

[Figure 1 about here]

Our country level analysis is therefore based on a more structural two-stage least square (2SLS) approach which is similar in spirit to the analysis of Feng et al. (2010), though we depart 
in some important respects. Two-Stage least squares (2SLS) regression analysis is the statistical technique that extends the popular Ordinary Least Squares (OLS) method. The technique is used when the dependent variable's error terms are correlated with the independent variables. If OLS were used, the estimated coefficients would be biased, and therefore unreliable. In the present context, the two-stage approach is necessary, as agricultural outcomes tend to be endogenous to the migration decision. Indeed, every migration shock induced by reasons different from the agricultural channel will have a direct effect on agricultural productivity. Under these circumstances, standard OLS methods will be biased because the error term is correlated with the variable of interest, namely agricultural outcomes. To solve this problem, and to test whether climate shocks have an effect on migration mediated by the agricultural channel, we first regress climate variables on agricultural outcomes. The predicted agricultural outcomes from this first stage regression are then used as instrument in the second stage migration equation.

Stated formally, our 2SLS baseline empirical model can be written as follows:

$$
\begin{aligned}
& x_{i t}=\boldsymbol{W}_{i t}^{\prime} \gamma+\boldsymbol{Z}_{i t}^{\prime} \boldsymbol{\delta}+f_{t}+c_{i}+v_{i t} \\
& m_{i t}=\beta x_{i t}+\boldsymbol{Z}_{i t}^{\prime} \boldsymbol{\theta}+f_{t}+c_{i}+\epsilon_{i t}
\end{aligned}
$$

Here, the (log) of agricultural output or productivity is given by $x_{i t}$. We aim at estimating an unbiased $\beta$ coefficient from equation (3) that represents the elasticity of net emigration with respect to agricultural outcomes, i.e. agricultural productivity or output (the red arrow in figure 1). However, any increase in the rate of emigration from rural areas, for reasons other than agricultural shocks (e.g. conflicts), will directly reduce the level of agricultural outcomes. Hence, in our first stage equation (2) the agricultural endogenous variable, $x_{i t}$, is assumed to be a function of weather shocks, $\boldsymbol{W}_{i t}^{\prime}$, which represent our instruments (the blue arrow in Figure 1). In other words, in the first stage we study how variations in climate change may have an effect (positive or negative) on agricultural outcomes, and, therefore, how these effects may impact on migration.

Both the first and the second stage equations (2)-(3) include a vector of controls, $\boldsymbol{Z}_{i t}^{\prime}$, and a full set of year, $f_{t}$, and country, $c_{i}$, fixed effects. Finally, $\varepsilon_{i t}$ and $v_{i t}$ are the error terms of the two 
equations assumed to be uncorrelated with one another. On the basis of equations (2) and (3) we purport to test whether the effect of climate change on migration is mainly indirect and mediated by the agricultural channel. In this respect, it is apparent that by substituting (2) into (3) we obtain the reduced-form relationship between weather and migration given in (1), where the possibly fundamental role of agriculture is subsumed.

Note that, by including country fixed effects, we control for time-invariant country specific factors, such as proximity to destination countries, network effects and other unobserved factors that could affect the migration process. In addition, time fixed effects address all common factors that could affect both agriculture and migration trends, such as technological progress and changes in agricultural policies (due to international price movements) as well as overall economic conditions both at origin and destination. Intuitively, only variations in agricultural outcomes that are associated with changes in climate are used to estimate the effect of agriculture on migration in the model.

The most critical assumption is the validity of our instruments, $\boldsymbol{W}_{i t}^{\prime}$, namely their relevance and exogeneity (exclusion restriction). As it is well known, relevance implies that our instruments should be sufficiently correlated with the instrumented variable, i.e. $\operatorname{corr}\left(\boldsymbol{W}_{i t}^{\prime}, x_{i t}\right)=0$, so that the first stage equation (2) is consistently identified. The exclusion restriction, instead, with reference to equation (3), requires instruments not to have any direct effect on the outcome variable (emigration), other than the one mediated by the agricultural channel, i.e. $\operatorname{corr}\left(\boldsymbol{W}_{i t}^{\prime}, \epsilon_{i t}\right)=0$, after controlling for relevant covariates.

That weather variations affect (non-linearly) agricultural productivity is well established, given the large amount of evidence from agronomic models and, in the last decades, from the climate econometrics literature (see Auffhammer and Schlenker, 2014). In particular, as explained above, the first stage (as well as the second stage) equation is identified by exploiting gradual (decennial) changes in weather on gradual changes in agricultural productivity (and migration). Because our econometric specification is always conditioned on year and country fixed effects, the estimated parameters of interest are identified from the country-specific decennial deviations in weather from the country-specific means, after controlling for shocks common to all countries. Under these conditions, the general idea is that weather variation is 
orthogonal to unobserved determinants of agricultural outcomes, a standard assumption made in the literature (see Dell et al., 2014).

More problematic is, in principle, the exclusion restriction of our instruments, namely that weather variations affect the migration decision only through their effects on agricultural outcomes. This is because there is evidence showing that climate variability may affect a number of different economic and social outcomes potentially inducing people to migrate, including economic growth and political instability (Dell et al., 2012), conflicts and wars (Burke et al., 2015a), and health outcomes (Deschenes and Moretti, 2009). In view of this fact, in our specification we always control for these additional potential channels by including per capita GDP (in log), political institutions, conflicts and wars, and a health indicator. The inclusion of these additional control variables is crucial for the credibility of our identification assumption and represent, together with the inclusion of time fixed effects, a key departure from Feng et al. (2010). Thus, we rely on a conditional independence instrumental variables strategy, according to which the exclusion restriction holds true only conditional on the inclusion of the set of controls $\boldsymbol{Z}_{i t}^{\prime}$, i.e. $\operatorname{corr}\left(\boldsymbol{W}_{i t}^{\prime}, \epsilon_{i t} \mid \boldsymbol{Z}_{i t}^{\prime}\right)=0$.

We apply our specification (2)-(3) to data on a sample of countries which, following a common practice in the literature, excludes OECD nations, given their particular status and because they are largely migration-receiving countries. In addition, in consideration of Cattaneo and Peri (2016)'s findings, we estimate our model separately for three different country samples: (i) an "Overall" sample that includes all non-OECD countries for which data are available; (ii) a "Poor" country sample based on the previous one that is comprised of only countries with per capita GDP below the median; and (iii) a "Middle-Poor" income country sample with countries having per capita GDP above the median of the overall sample distribution. Finally, because the split of the overall sample between poor and middle-income countries based on the median of per capita GDP is admittedly an arbitrary choice, we will test the extent to which our baseline results are robust to alternative definitions of poor and middle-poor countries.

\section{Data and summary statistics}

In view of the empirical analysis we compile a panel dataset, which covers all available 
countries from 1960 to 2010 by merging different sources of data from which our key variables come from. We separate the overall sample into one including only poor countries (Poor), taken to be those belonging to the first and second quartiles of the per capita income distribution in 1970, and one with middle income (Middle-Poor) ones which are those in the third and fourth quartiles. We end up with an overall sample of 108 countries of which 60 are poor and 48 are middle-poor. The list of countries is reported in Table 1.

[Table 1 about here]

To begin with, data on international migration were taken from Özden et al. (2011). This dataset is a global matrix of bilateral migrant stocks from 115 countries to 115 countries spanning the period from 1960 to 2000 with ten-year intervals. We extended it to include 2010 using estimates from the same World Bank sources, so that we can benefit from one more decade of observations. The data are decadal due to the fact that the original sources are national Censuses. As note by, among others, Cattaneo and Peri (2016), these data are much more accurate in counting foreign-born individuals than flow measures and they allow us to study the long-run relationship between agricultural outcomes, weather variability and migration behavior. We construct our dependent variable by first summing all emigrants from each origin country and then computing the emigration rate as the ratio between the aggregate net outflow and the origin country population at the beginning of each period. More precisely, the (log of the) emigration rate $m$ is equal to $m_{i t}=\log \left(\frac{M_{i t}}{P_{\text {op }}}\right)$, with $M_{i t}$ being the number of migrants from country $i$ at time $t$ (computed as the difference between stocks in two consecutive Censuses) and $P o p_{i t}$ the total population of country $i$ at time $t$. In doing so bilateral net flows that are negative are set to equal to zero. As shown in Table 2, the average migration rate in the period considered (1960-2010) for the overall sample is equal to $2.9 \%$. This value is equal to $2.4 \%$ for poor countries and to $3.5 \%$ for the middle-poor ones.

Secondly, data on mean temperature and precipitations are taken from Burke et al. (2015b), which extend the Dell et al. (2012) dataset. These variables are expressed as population- 
weighted average annual temperature in degrees Celsius, while precipitations are in millimeters. We also used temperature and precipitations expressed in area-weighted terms with results qualitatively similar (available upon request). This dataset is the result of aggregation at the country level of worldwide monthly mean temperature and precipitations data with a $0.5 \times 0.5$ degree resolution. Values are interpolated for each grid node from an average of 20 different weather stations, corrected for elevation. We calculate the mean temperature and precipitations over ten years, harmonizing this part of the dataset with the one on migration.

In our baseline regressions we use the average temperature and precipitations data just described. However, because in previous analyses other weather indicators have been used, as a robustness check we also considered the (decadal) standard deviation of temperature and of precipitations, to capture extreme weather values, defined as the number of years in a decade in which the temperature (same for precipitations) was above two standard deviations of the 1960-2010 period mean for the country (see Feng et al. 2010).

Our third source of data pertains to agricultural output and agricultural productivity. In the former case we obtain gross production values measured in constant 2004-2006 international dollars from FAOSTAT, create the mean value over ten years, and take the logarithm of this variable. In the latter case we compute the logarithm of the ratio between agricultural output and hectares of agricultural land.

Figure 2 shows that variations in agricultural output/productivity and emigration rates tend to move in opposite directions in the case of poor countries, so that a decrease in the agricultural output is inversely related to the emigration rate. A similar, though less pronounced pattern is shown for middle-poor countries in Figure 3. Thus, the raw data appear to support the idea that an agricultural shock (i.e. lower productivity growth) increases the rate of outmigration, a relationship apparently stronger for poor countries.

[Figure 2 about here] 
[Figure 3 about here]

Table 2 reports summary statistics for all variables considered in our empirical analysis for all countries and separately for poor and middle-poor countries. It is immediately seen that agricultural output and agricultural productivity are higher in middle-poor countries, while temperature and precipitations are higher in poor countries.

[Table 2 about here]

The vector of control variables, $\boldsymbol{Z}_{i t}^{\prime}$, that we include in the econometric investigation consists of four variables. Firstly, since the theory underlying our research design emphasizes climatedriven income effects as a key determinant of the emigration decision, it is important to control for the (log) of GDP per capita when testing the robustness of the agricultural channel. We take the data from the Penn World Tables in constant 2000 PPP. Secondly, we control for conflicts and wars, whose data are taken from the Arms \& Conflict database, as there is evidence that climatic conditions may increase the probability of conflicts (Hsiang et al., 2013; Burke et al., 2015a). Conflicts and wars are indeed a primary source of migration decision (see, e.g., Adhikari, 2013; Brzoska and Fröhlich, 2016) and could affect directly agricultural productivity. In addition, a few papers have shown how, in the modern warm period, the increase in temperature fosters collective violence, such as land invasions in Brazil (Hidalgo et al., 2010) or civil war intensity in Somalia (Maystadt and Ecker, 2014). Thirdly, we control for the quality of political institutions using the Polity II index on the quality of democracy taken by the Polity IV database (see Marshall and Jaggers, 2007). A regime change toward autocracy may clearly affect emigration directly, an impact that could be especially severe for rural people because there is evidence showing how autocratic governments tax the agricultural sector heavily (Olper et al., 2014). Furthermore, Dell et al. (2012) find evidence that higher temperatures induce a general reduction in the quality of democracy or a deterioration of the quality of autocracy in poor countries, bringing more political instability and less growth (Alesina et al., 
1996). Fourthly, as a final control we add to our specification health outcomes, as measured by life expectancy at birth, whose data come from the World Bank. Here the presumption is that adverse weather shocks, induced by very hot (or very cold) temperature, by affecting mortality, morbidity and early life (Carleton and Hsiang, 2016), could induce people to migrate (Marchiori et al., 2012). Note that the effect could be both direct, i.e. people choose to migrate to cope with the physiological effects of high (low) temperature, but also could be indirect through the agricultural channel. This is because working in agriculture, especially in poor and middleincome countries, being an outdoor activity, is affected by weather conditions more than other working indoor.

Table 2 reports additional statistics that better substantiates our tenet, that agriculture could be an important mediating factor in the nexus between climate and migration. From this perspective, the differences between poor vs. middle-poor countries highlight some interesting patterns. First, and not surprising, poor countries are characterized by an agricultural share over GDP (30.8\%) that is more than twice higher than the middle-poor sample (12.5\%). In principle the larger the importance of agriculture, the larger the potential impact of a climate shock in affecting the migration decision, as recently argued by several papers (e.g. Feng et al., 2010). Second, the vulnerability of agriculture to climatic shocks, measured as the proportion of the agricultural area with irrigation (taken from the FAO Food Security Indicators) is only $15.7 \%$ in the poor countries sample, but rise to $24 \%$ in the middle-poor ones, suggesting once again important differences between the two sub-samples. Yet, populations most exposed and vulnerable to the impacts of climate change may have the least ability to migrate (Black et al., 2013), though this relationship can be strongly non-linear.

Table 2 reports also an export diversification index taken from UNCTAD. Ideally a diversification index of agricultural production is more appropriate than the export diversification index reported in Table 2. However, the necessary data for our samples are difficult to find. In addition, to the extent that what a country exports is closely related to what a country produces, the two indices will be highly correlated. Values closer to 1 indicate greater divergence from the world export pattern, and thus a low degree of diversification of an economy's production and export activities. With an index equal to 0.74 the poor countries are less diversified than middle-poor ones, where the index is equal to 0.71 , though the difference 
is not so relevant. In general, more diversified economies (lower index) ought to be more resilient to climate shocks and this could hamper the migration response. Another index we report in the table has to do with diaspora effect, namely the idea that the size of the networks at destination matters for the migrants' selection. For example, Beine et al. (2011) show that the stock of people born in a country and living in another one (network), increases the migration flows and lowers their average educational level. The network index, taken from Docquier et al. (2007), is equal to 0.37 for the sample of poor countries and to 0.65 for the middle-poor sample. This pattern may suggest that the reason why poor people especially from Africa (the poorest region in our sample) emigrate less is also due to their lack of external available resources, such as migration networks. We finally note that extreme value of (high) temperatures and (low) precipitations affect more poor countries than middle-poor ones.

\section{Empirical results}

\subsection{Reduced-form and OLS results}

To motivate our empirical approach, we start by estimating an equation in which the logarithm of the emigration rate is regressed directly on our weather variables, controlling for year and country fixed effects. This corresponds to the reduced-form equation (1), obtained - as said in Section 4 - from substituting (2) into (3). We have previously noted that this is the basic representation of much of the literature on the migration-weather nexus. Finding a consistent reduced-form relationship should be view as a pre-condition in support of our 2SLS approach (Agrist and Pischke, 2008). Note that we allow for potential non-linear impacts of weather on migration by including squared temperature and precipitations as explanatory variables.

In this reduced-form regression we use a parsimonious specification that does not include control variables other than country and year fixed effects (see Dell et al., 2014; Hsiang, 2016). This is because several controls such as agriculture, economic, political and demographic variables may themselves be affected by climate variables: including them could induce a bias in the estimation due to an over-controlling problem (Hsiang, 2016).

Table 3 presents the estimation results for the full sample in column (1), for the sample of poor 
countries in column (2) and for middle-poor countries in column (3).

[Table 3 about here]

Looking at the overall sample, we see that the emigration rate is increasing in temperature, but at a decreasing rate. This non-linear pattern is statistically significant, unlike the effect of precipitations. A second important result is that weather variables, and particularly temperature, are significant at 5\% confidence level for the overall sample and at $1 \%$ level for poor countries but are not significant for the middle-poor ones. We thus find that an increase in temperature over the trend, during a 10-year period, induces people especially from poor income countries to emigrate, an effect estimated with great precision. The turning point of the relationship is around $23^{\circ} \mathrm{C}$ for both the overall and the poor country samples. This value is close to the $23.5^{\circ} \mathrm{C}$ found by Feng et al. (2010) when studying emigration from Mexico to the U.S. and also to the $25^{\circ} \mathrm{C}$ level found by Bohra-Mishra et al. (2014) who considered interprovincial migration in Indonesia. Taken together, these reduced-form results are qualitatively consistent with the previous findings, showing that emigration is mainly affected by temperature in a non-linear fashion, and less so by precipitations, even if our findings mainly hold for poor income countries, a result somewhat at odds with the liquidity constraint interpretation of Cattaneo and Peri (2016).

We next focus on the relationship between migration and agriculture. Table 4 presents fixed effects (FE) OLS estimation results where we regress the emigration rate on our variables of interest, agricultural output or productivity. As before, we consider the overall sample and respectively the poor and middle-poor sub-samples separately. We now add the vector of controls discussed in the previous section because, to study if the agricultural channel is relevant, we need to keep constant the standard drivers of migration. These regressions serve as a reference for our 2SLS research design, which is presented in the next sub-section.

[Table 4 about here] 
When measured as production output, the effect of agriculture on migration is negative and strongly significant (1\% level) in both the overall and the poor sample but not significant in the middle-poor one. A similar pattern is found if we use agricultural productivity as a regressor: a reduction in agricultural productivity increases the rate of emigration, and the effect is now significant also for middle-poor countries (see Column 6). Thus, controlling for country and time fixed effects and the standard drivers of migration, what happened in the agricultural sector appears to be very important for the decision to emigrate, an effect especially robust both for the overall sample, and the poor sub-sample. What is also relevant from the results of Table 4 is that the other control variables included in the equation, though often with the expected sign, are not statistically significant when agriculture variables are controlled for.

Quantitatively, the estimated elasticity implies that a $1 \%$ reduction below the trend in agricultural output (or productivity) over a 10-year period induces an increase of the emigration rate ranging from about $0.5 \%$ to $0.8 \%$ in the overall and poor samples, respectively. Interestingly, the size of this (OLS) effect is of the same order of magnitude as the 2SLS estimate by Feng et al. (2015) for U.S. internal migration.

As discussed above, the estimated effect of agriculture on the emigration rate could be biased due to reverse causality problems, as any variation in the emigration rate due to reasons other than agricultural shocks will affect directly agricultural production and productivity. In addition, these OLS estimates may suffer from omitted variable bias induced, for example, by international price shocks and the government reaction to these shocks through agricultural protection policies (Olper et al., 2014), both factors that could increase or offset the migration responses. By moving from simple OLS to 2SLS regressions we now carefully address these issues.

\subsection{Two-stage least squares (2SLS) results}

Table 5 reports the second stage results of estimating the system of equations (2) and (3). The corresponding first stage results are displayed in Table 6. As before, results are shown for the all country sample, and separately for the poor and the middle-poor sub-samples, considering both our alternative agricultural variables of interest. All regressions include time and country 
fixed effects and our set of controls. Results from Columns (1) to (6) of Table 5 refer to 2SLS estimator, while Columns from (7) to (12) report Limited information maximum likelihood (LIML) estimator, that is robust to weak instruments problems.

[Table 5 about here]

We first address the issue of the relevance of our instruments and look at the evidence reported at the bottom of the table. We can see that the p-value of the under-identification test suggests that the excluded instruments are relevant in all the specifications, confirming that they are correlated with the endogenous regressors. The Kleibergen-Paap Wald F-statistic for the weak identification of our instruments does not satisfies the Stock et al. (2002) critical value of around 10 for the 2SLS estimator but are close to the critical values of the LIML estimator (see Stock and Yogo 2005, Table 5.3). This potential problem of weak instruments is probably the result of the quality of climatic (and agricultural) data, which is notoriously low in poor and middle-income countries.

We consider other two additional weak instrument tests. First, the Anderson and Rubin (1950) AR test statistics is shown to always reject the null hypothesis that the coefficients of our endogenous variables in the structural equation are equal to zero. Second, we compute the Fractionally re-sampled Anderson and Rubin (FAR) test recently proposed by Berkowitz et al. (2012) which is able to obtain valid, but conservative, inferences when the instruments do not perfectly satisfy the exclusion restriction in the second stage. In our specifications, the FAR test rejects systematically the hypothesis that the second stage coefficient is zero at $1 \%$ level of significance, thus confirming that our instruments do a good job at identifying the first stage equation.

Our 2SLS results strongly confirm that climate-driven changes in agricultural outcomes affect significantly net migration outflows, so that a decrease in agriculture production induced by climate shocks leads individuals to migrate. Interestingly, and consistently with the reducedform results, this effect is only relevant for the overall sample (Columns 1 and 2) and for the 
poor country sample (Columns 3 and 4), where technological adaptations are absent and migration may be considered a plausible coping strategy. No effects are detected for middlepoor countries where the estimated coefficients of agricultural variables are still negative, thus pointing in the same direction, but are never statistically significant (see Columns 5 and 6).

Results in Tables 5 and 6 clearly show that there is a causal link between the increase in temperature, acting through agriculture, on migration. This is because only variations in agricultural outcomes that are associated with changes in climate (equation 3) are used to estimate the effect of agriculture on migration (equation 2). In other words, our two-stage strategy firstly shows that climate significantly influences agricultural productivity (Table 6) and secondly that agricultural productivity shocks (driven by climate) significantly induce migration (Table 5). Figure 1 represents the conceptual analysis of the empirical climateagriculture-migration nexus just described.

The magnitude of the 2SLS estimated effect of agriculture is more than 5 times larger than that of the corresponding OLS effect seen in the previous Table 4. For example, considering Columns 3 and 4, a 1\% decrease in agricultural production (resp. productivity) below its trend, over a 10-year period, induces an additional 4.7\% (resp. 5.0\%) increase of the emigration rate, an economically sizeable effect. In comparison, when middle-poor countries are considered, the estimated agricultural effect on emigration is never statistically significant, but still negative and with a magnitude close to that of the OLS results. The marked difference between OLS and 2SLS estimated size effects is noteworthy, because in presence of weak instruments the estimated coefficient of 2SLS should converge toward the OLS one (see Angrist and Pischke, 2008). In fact, this is never the case in our regression results, where the 2SLS coefficients of the agricultural variables are systematically larger than the OLS ones.

Since our instruments do not pass the critical F-test for the 2SLS estimator (though the AR and FAR tests are significant), it is important to check also the LIML results (see Columns 7-8). The LIML estimator is approximately median unbiased for over-identified constant effects model and possesses the same asymptotic distribution as the 2SLS, but also a finite sample bias reduction, implying less bias in the estimated error relative to 2SLS. In practical terms, if the LIML estimates are close to the 2SLS ones in terms of the magnitude of the estimated 
coefficients and standard errors, there is no reason to worry (see Agrist and Piscke, 2008). This is indeed our case, as the LIML estimates are qualitative and quantitatively similar to the 2SLS results, for both our agricultural variables of interest. Thus, the LIML results, together with those of the reduced-form equations and the large difference between the OLS and 2SLS coefficients, all pointing in the same direction, represent a confirmation of the robustness of our key findings.

Before concluding this section, it is important to briefly consider the first stage results, to check if the agricultural channel story is also consistent with them. Table 6 presents the evidence.

[Table 6 about here]

It is seen that temperature and its square have the expected non-linear effect on agricultural production, an effect that is strongly significant especially for the poor country sample. Precipitations are never statistically significant in these specifications, a result somewhat counterintuitive as drought tends to be an important driver of famine and food insecurity. Thus, there are some effects that might be missed in the above specifications which uses country average precipitations. We return to this issue in the next section.

Finally, it is important to note that for the overall sample and for the poor country one, the impact of temperature is such that an increase strongly reduces agricultural output and productivity, but at a decreasing rate. This is exactly the relationship we should expect given the reduced-form results of Table 3. In fact, because agricultural productivity shocks affect negatively migration, the reduced-form and first stage impact of temperature should go in an opposite direction, inverted U-shaped in the former case and U-shaped the latter case. In addition, the turning point of the relationship in the first stage of the poor sample is around $24^{\circ} \mathrm{C}$, close to the one estimated in the reduced-form equation, equal to $23^{\circ} \mathrm{C}$. All these findings are supportive of the importance of the agricultural mechanism for explaining the dominant effect of temperature on migration, because indeed temperature has a similarly dominant influence on agricultural conditions. 


\section{Robustness checks and extensions}

\subsection{Results using different country classifications}

The evidence presented before shows that negative climate-driven shocks to agriculture spur emigration from poor countries, but not from middle-poor ones; in the latter case the results point in the same direction but are not statistically significant. Overall, this evidence is fairly consistent with a large micro and macro literature on climate change and migration (see Berlemann and Steinhardt, 2017), but it is at odds with the liquidity constraints argument according to which negative income shocks especially in poor and most vulnerable countries can trap population, thereby preventing emigration.

A first reason for this apparent inconsistency could be due to our chosen country classification. Admittedly, our classification based on the 1970 median per capita GDP is arbitrary. As a robustness check, therefore, we present additional results stemming from alternative sample splits. This sensitivity analysis is summarized in Figure 4, where 2SLS estimated coefficients of our two agricultural variables are represented as colored dots, together with their significance level and 95\% confidence interval (colored bar). In the Appendix of this paper we report all regression results corresponding to the robustness checks summarized in Figure 4 (we report the regression results of both second stage - equation (3) and first stage (equation (2)). The first blue dot starting from the left represents our baseline estimates, reproducing the 2SLS coefficients of Table 5, Columns from 3 to 6 , respectively.

[Figure 4 about here]

On the whole, the results displayed in the figure appear to be fairly robust. Using the median per capita GDP in 1990, instead of 1970, the results are qualitatively very close (red dot). We detect just a reduction in the size of the estimated impact for the poor country sample, from 4.7 (resp. -5.0) when agricultural output (resp. productivity) is used to -4.0 (resp. -2.9), probably due to the contribution of countries that entered the dataset in 1990, inducing a 
change in the composition of the poor sample. However, the estimated effects for the poor sample remain highly significant.

We next consider two additional alternative splits. The first one is based on the World Bank income classification of 1990, where countries labeled as "lower income" and "lower middle income" are considered within the poor sub-sample, while all other countries are classified as middle-poor (green dots). The second criterion is based on the quartiles of the 1970 income distribution, with countries of the first quartile (Q1) classified as poor, and those of other quartiles $(\mathrm{Q} 2+\mathrm{Q} 3+\mathrm{Q} 4)$ classified as middle-poor (orange dots). These two classifications produce a significant change in the composition of our two sub-samples, biased toward an over- (resp. under-) representation of countries in the poor (resp. middle-poor) sub-sample. Notwithstanding this changes, the results point in the same direction as our reference ones, showing just a reduction of the magnitude of the estimated effect when the definition of poor countries become sharper. The magnitude of the estimated coefficient of agricultural variables for the poor sub-sample is now around -3.5 for the World Bank classification, a value that goes down to around -2.3 when the poor sample include only countries belonging to the Q1 of the income distribution. Thus, we find evidence that when the definition of poor countries becomes more restrictive the size of the estimated effect shrinks, suggesting that some liquidity constraints effect may be driving the results. Yet, the data still show that climate-driven negative shocks in agriculture increase emigration also in this more restrictive poor countries definition.

Our baseline results have been obtained on the basis of data whose time coverage was extended to include 2010 relative to the Ozden et al. (2011) dataset, by adding the last migration matrix data produced by the World Bank. Though the basic source of the two datasets is the same, it is well known that migration datasets are always problematic. Thus, it could be interesting to see if our findings hold with a more restrictive 1960-2000 sample. The light green dots in Figure 4 report on this additional robustness check. The estimated effect is indeed still negative for the poor country sample with a size of the estimated effect within the range of the previous findings. Of course, by reducing the size of the sample the precision of the estimates is somewhat reduced, as one less decadal observation may entail an important loss of 
information. While the effect is significant at $5 \%$ level when agricultural productivity is used, it is no longer statistically significant when agricultural output is considered, though the estimated coefficient is still negative and with a similar order of magnitude. The reduction in the precision of the estimates is not surprising when using a 2SLS estimator on a smaller sample (reduced degrees of freedom), given the well-known problem of larger standard errors of 2SLS estimates in presence of weak instruments. Importantly, the fact that the size of the effect is similar to our reference one is reassuring and suggests that results of this reduced sample point in the same direction.

A crucial robustness check to directly assess if agriculture is the channel through which climate affects migration consists of splitting the overall sample according to the median value of the share of agriculture in total GDP. Indeed, if another channel through which climate affect emigration were at work in our estimates and operated in the same direction as through agricultural productivity shocks, we would see our estimates to be biased upward in absolute value. This it is not the case, as these additional results clearly show for both our agricultural variables (light red dots), the size of the estimated effect just shrink marginally when the agricultural output is used as endogenous variable, and it is close to our baseline when agricultural productivity is used. Thus, if anything, the magnitude of this bias seems to be low in our sample, reinforcing the idea that what we are pick up in our regressions is, indeed, a genuine agricultural channel.

A further robustness check considers the vulnerability of the agricultural sector, measured as the proportion of agricultural area under irrigation. The general idea is that populations most exposed and vulnerable to the impacts of climate change may have less ability to migrate (Black et al., 2013). If this is the case, then by splitting the sample using the median value of this dimension we should find a less negative agricultural effect in the poor sub-sample and a more negative one in the middle-poor sample. Violet dots in the figure show that vulnerability seems to matter, in the sense that the size of the agricultural effects in the poor sample is now significant lower, and equal to around -2.5 , though it remains negative and highly statistically significant. In addition, there is clear evidence that in less vulnerable countries climate-induced agricultural shocks spur emigration, though this effect is estimated with very low precision. 
Lastly, we investigate whether our main findings are robust to the use of different climate variables, as used by previous analyses (see Feng et al., 2010; Cattaneo and Peri, 2016; Beine and Parsons, 2015). Specifically, other than average temperature and precipitations, we also consider the decadal standard deviation (SD) of both variables (sand color dots) as well as extreme temperature and precipitations (brown dots), defined as the number of years in a decade in which temperature and precipitations were above two standard deviations of the 1960-2010 period mean for the respective country. Admittedly, and considering especially precipitations, a better index to identify the agricultural outcomes shocks might be one

accounting also for the temporal variability accumulated over the decade of interest (see Brown et al., 2011).

As it is clear from Figure 4, using these additional weather instruments the estimated semielasticities of the climate-induced agricultural shock on migration remain very close to the baseline values and are estimated with great precision. Furthermore, and in line with the findings of Brown et al. (2011), when precipitations are included in the model considering also their temporal variability, the impact on agricultural outcomes become significant and negative in several specifications (see the Tables A.15 and A.16 of the Appendix for the empirical results). Overall, the last result appears more logical from an agro-climatic point of view, suggesting that temporal variability captures effects that might be missed in the analysis when using only country average precipitations over a decade.

\subsection{Alternative channels}

The validity of our 2SLS results strongly depends on the assumption that our instruments, i.e. climate variables, have no direct effect on current emigration rates, after controlling for (instrumented) agricultural production and including country and time fixed effects, plus key controls highlighted by previous literature. Although we have argued at great length that this assumption is plausible, we can assess the evidence by running a sort of horse race between alternative channels and the agricultural one. To that end we implement a simple test, namely we use our climate instruments to endogenize each alternative channel in a specification identical to the one reported in Table 5, but where each concurrent alternative is treated as endogenous, and therefore instrumented with climate variables. The regression results of this 
exercise are reported in Table 7.

[Table 7 about here]

The results are remarkable, in the sense that no other control, treated as an endogenous variable, turns out to be significantly different from zero, while the (non-instrumented) agricultural variable is systematically negative, often significant, and with an order of magnitude close to or higher than the OLS estimates reported in Table 4. Note, this is an important test in support of the relevance of the agricultural channel.

Summarizing, on the basis of this additional evidence and considering also the previous sensitivity analysis, we may conclude that our main finding, pointing to an important role of the agricultural sector in mediating the climate-migration nexus, appears to be robust to alternative interpretations.

\section{Discussion and conclusions}

This paper has been motivated by the recent and growing literature on the relationship between climate variability and migration. At both micro and macro levels a growing body of research has established the existence of an empirical link between weather variables, such as temperature and precipitations, and migration decisions. Several studies emphasize the agricultural sector as one of the main mediating channel through which climate change may affect migration. To date no paper, especially at the macro level, has tested the structural relationship linking climate-driven changes in agricultural outcomes to migration decisions. In this paper we explicitly tested whether changes in agricultural outcomes induced by decennial variations in temperature and precipitations, are at the root of climate-induced international migration decisions.

We find a strong confirmation to this hypothesis using both OLS and 2SLS approaches. Our preferred second stage results indicate that, on average, climate-driven reduction in 
agricultural productivity of $1 \%$ from its decennial trend induces an increase in the emigration rate from about $2.5 \%$ to about $4.5 \%$ in the overall and poor country sample, respectively, whereas for middle income countries the effect is never statistically significant. This migration elasticity to agricultural outcomes is precisely estimated and it is robust to the use of different agricultural variables (overall output and productivity per hectare) and to the addition of several covariates suggested by the literature as plausible determinants of emigration. Quantitatively, our findings show that the 2SLS effect is about four times larger than the OLS one suggesting that, by not considering the endogeneity of agricultural variables relative to the migration decision, one significantly underestimates the magnitude of this elasticity. This is a result of the present study with potentially relevant implications. In fact, the size of future impacts of global warming, especially in agriculture and for the many countries relying on income from that sector, is a critical ingredient for climate change mitigation and adaptation policies.

Finally, contrary to some previous findings (such as Cattaneo and Peri, 2016), our results show that the climate-agricultural-migration nexus is particularly strong for poor and most vulnerable countries, where the agricultural sector represents the main income stream of the population, is more vulnerable to climate shocks, and where people are more likely to use migration as an adaptation response strategy. This result is consistent, and extends, several previous studies based on reduced form estimates showing that the climate-migration relationship holds true particularly in agriculture-dependent countries (see Maurel and Tuccio, 2016; Cai et al. 2016; Mastrorillo et al. 2016).

Understanding the extent to which climate-induced changes in agricultural outcomes cause migration is very important from a policy perspective. This is because any policy action aimed to mitigate the effect of climate change on migration flows needs to be well informed about the main channels at work. Using a particular research design and after several robustness checks, we argue that our main finding has a causal interpretation. However, it is also important to keep in mind the limitations of our analysis.

Firstly, we are not arguing that climate-driven changes in agricultural outcomes are the only factor affecting migration decisions, but there exist other potentially important determinants of 
migration flows, as suggested by a large literature. Secondly, in our framework the role of agriculture as key mediating channel emphasizes direct income effects, i.e. how agricultural income shocks driven by climate, change the opportunity costs to stay or to migrate. Admittedly, though this can be one of the relevant mechanisms, there are reasons to believe that the transmission channel from agricultural income shocks to migration is more complex, differentiated across countries, and involving other key variables, such as food security and vulnerability, resource conflicts and/or farm holdings heterogeneity. Future work should be directed to better understand the mechanism through which weather-induced changes in agricultural income affect migration decisions in developing countries.

\section{References}

Adger, W.N., J.M. Pulhin, J. Barnett, G.D. Dabelko, G.K. Hovelsrud, M. Levy, Ú. Oswald Spring, and C.H. Vogel, (2014): Human security. In: Climate Change 2014: Impacts, Adaptation, and Vulnerability. Part A: Global and Sectoral Aspects. Contribution of Working Group II to the Fifth Assessment Report of the Intergovernmental Panel on Climate Change [Field, C.B., V.R. Barros, D.J. Dokken, K.J. Mach, M.D. Mastrandrea, T.E. Bilir, M. Chatterjee, K.L. Ebi, Y.O. Estrada, R.C. Genova, B. Girma, E.S. Kissel, A.N. Levy, S. MacCracken, P.R. Mastrandrea, and L.L. White (eds.)]. Cambridge University Press, Cambridge, United Kingdom and New York, NY, USA, pp. 755-791.

Adhikari, P. (2013). Conflict-induced displacement, understanding the causes of flight. American Journal of Political Science, 57(1): 82-89.

Alesina, A., Özler, S., Roubini, N., and Swagel, P. (1996). Political instability and economic growth. Journal of Economic Growth, 1(2): 189-211.

Anderson, T. W. and Rubin, H. (1950). The asymptotic properties of estimates of the parameters of a single equation in a complete system of stochastic equations. The Annals of Mathematical Statistics, 21(4): 570-582.

Angrist, J. D. and Pischke, J.-S. (2008). Mostly harmless econometrics: An empiricist's companion. Princeton University Press.

Auffhammer, M. and Schlenker, W. (2014). Empirical studies on agricultural impacts and adaptation. Energy Economics, 46: 555-561.

Auffhammer, M. and Vincent, J. R. (2012). Unobserved time effects confound the identification of climate change impacts. Proceedings of the National Academy of Sciences, 109(30): 1197311974. 
Beine, M. and Jeusette, L. (2018). A meta-analysis of the literature on climate change and migration. University of Luxembourg CREA Discussion Paper N. 2018-05.

Beine, M. and Parsons, C. (2015). Climatic factors as determinants of international migration. The Scandinavian Journal of Economics, 117(2): 723-767.

Beine, M., Docquier, F. and Özden, Ç. (2011). Diasporas. Journal of Development Economics, 95 : 30-41.

Berkowitz, D., Caner, M., and Fang, Y. (2012). The validity of instruments revisited. Journal of Econometrics, 166(2): 255 - 266.

Berlemann, M. and Steinhardt, M. F. (2017). Climate change, natural disasters, and migration -A survey of the empirical evidence. CESifo Economic Studies, 63(4): 353-385.

Black, R., Adger, W. N., Arnell, N. W., Dercon, S., Geddes, A., and Thomas, D. (2011). The effect of environmental change on human migration. Global Environmental Change, 21: S3-S11.

Black, R., N.W. Arnell, W.N. Adger, D. Thomas, and Geddes, A. (2013). Migration, immobility and displacement outcomes of extreme events. Environmental Science and Policy, 27: S32-S43.

Bohra-Mishra, P., Oppenheimer, M., and Hsiang, S. M. (2014). Nonlinear permanent migration response to climatic variations but minimal response to disasters. Proceedings of the National Academy of Sciences, 111(27): 9780-9785.

Borjas, G. J. (1985). Assimilation, changes in cohort quality, and the earnings of immigrants. Journal of Labor Economics, 3(4): 463-489.

Borjas, G. J. (1987). Self-selection and the earnings of immigrants. American Economic Review, 77(4): 531-553.

Brown, C., R. Meeks, K. Hunu and W. Yu (2011). Hydroclimate risk to economic growth in subSaharan Africa. Climatic Change, 106(4): pp 621-647.

Brzoska, M. and Fröhlich, C. (2016). Climate change, migration and violent conflict: vulnerabilities, pathways and adaptation strategies. Migration and Development, 5(2): 190210.

Burke, M. and Emerick, K. (2016). Adaptation to climate change: Evidence from us agriculture. American Economic Journal: Economic Policy, 8(3): 106-40.

Burke, M., Hsiang, S. M., and Miguel, E. (2015a). Climate and conflict. Annual Review of Economics, 7(1): 577-617.

Burke, M., Hsiang, S. M., and Miguel, E. (2015b). Global non-linear effect of temperature on economic production. Nature, 527(7577): 235-239. 
Cai, R., Feng, S., Oppenheimer, M., and Pytlikova, M. (2016). Climate variability and international migration: the importance of the agricultural linkage. Journal of Environmental Economics and Management, 79: 135 - 151.

Carleton, T. A. and Hsiang, S. M. (2016). Social and economic impacts of climate. Science, 353(6304).

Cattaneo, C. and Peri, G. (2016). The migration response to increasing temperatures. Journal of Development Economics, 122: 127-146.

Coniglio, N. D. and Pesce, G. (2015). Climate variability and international migration: an empirical analysis. Environment and Development Economics, 20(04): 434-468.

Dell, M., Jones, B. F., and Olken, B. A. (2012). Temperature shocks and economic growth: evidence from the last half century. American Economic Journal: Macroeconomics, 4(3): 66-95.

Dell, M., Jones, B. F., and Olken, B. A. (2014). What do we learn from the weather? The new climate-economy literature. Journal of Economic Literature, 52(3): 740-98.

Deschenes, 0. and Greenstone, M. (2007). The economic impacts of climate change: evidence from agricultural output and random fluctuations in weather. American Economic Review, 97(1): 354-385.

Deschenes, 0. and Moretti, E. (2009). Extreme weather events, mortality, and migration. The Review of Economics and Statistics, 91(4): 659-681.

Dillon, A., Mueller, V., and Salau, S. (2011). Migratory responses to agricultural risk in northern Nigeria. American Journal of Agricultural Economics, 93(4): 1048-1061.

Docquier, F. and Rapoport, H. (2012). Globalization, Brain Drain, and Development. Journal of Economic Literature, 50(3): 681-730.

Docquier, F., Lowell, B.L., and Marfouk, A., (2007). A gendered assessment of highly skilled emigration. Population and Development Review 35 (2): 297-321.

Drabo, A. and Mbaye, L. M. (2015). Natural disasters, migration and education: an empirical analysis in developing countries. Environment and Development Economics, 20(06): 767-796.

FAO (2017). Migration, agriculture and climate change. Reducing vulnerabilities and enhancing resilience. Technical report, United Nations - Rome.

Feng, S., Krueger, A. B., and Oppenheimer, M. (2010). Linkages among climate change, crop yields and Mexico-US cross-border migration. Proceedings of the National Academy of Sciences, 107(32): 14257-14262.

Feng, S., Oppenheimer, M., and Schlenker, W. (2015). Weather anomalies, crop yields, and migration in the US corn belt, unpublished (http://www.columbia.edu/ ws2162/articles/Feng0ppenheimerSchlenker.pdf). 
Glaser, R.; Himmelsbach, I.; Bösmeier, A. (2017). Climate of migration? How climate triggered migration from southwest Germany to North America during the 19th century. Climate of the Past, 13: 1573-1592.

Gray, C. and Bilsborrow, R. (2013). Environmental influences on human migration in rural Ecuador. Demography, 50(4): 1217-1241.

Gray, C. and Wise, E. (2016). Country-specific effects of climate variability on human migration. Climatic Change, 135(3-4): 555-568.

Gray, C. L. and Mueller, V. (2012). Natural disasters and population mobility in Bangladesh. Proceedings of the National Academy of Sciences, 109(16): 6000-6005.

Gröschl, J. and Steinwachs, T. (2017). Do Natural Hazards Cause International Migration? CESifo Economic Studies, 639(4): 445-480.

Harris, J. R. and Todaro, M. P. (1970). Migration, unemployment and development: a two-sector analysis. American Economic Review, 60(1): 126-142.

Hidalgo, F. D., Naidu, S., Nichter, S., and Richardson, N. (2010). Economic determinants of land invasions. The Review of Economics and Statistics, 92(3):505-523.

Hornbeck, R. (2012). The enduring impact of the American Dust Bowl: Short- and long-run adjustments to environmental catastrophe. American Economic Review, 102: 1477-1507.

Hsiang, S. (2016). Climate econometrics. Annual Review of Resource Economics, 8: 43-75.

Hsiang, S. M., Burke, M., and Miguel, E. (2013). Quantifying the influence of climate on human conflict. Science, 341(6151): 1235367-1235367.

Hunter, L.M., Luna, J.K., and Norton, R.M. (2016). Environmental Dimensions of Migration. Annual Review of Sociology, 41: 377-97.

Jessoe, K., Manning, D., and Taylor, E. J. (2018). Climate change and labour allocation in rural Mexico: Evidence from annual fluctuations in weather. The Economic Journal, 128(608): 230261.

Kubik, Z. and Maurel, M. (2016). Weather shocks, agricultural production and migration: evidence from Tanzania. The Journal of Development Studies, 52(5): 665-680.

Lobell, D. B., Schlenker, W., and Costa-Roberts, J. (2011). Climate trends and global crop production since 1980. Science, 333(6042): 616-620.

Marchiori, L., Maystadt, J.-F., and Schumacher, I. (2012). The impact of weather anomalies on migration in sub-Saharan Africa. Journal of Environmental Economics and Management, 63(3): $355-374$.

Marshall, M. G. and Jaggers, K. (2007). Polity IV project: dataset users' manual. 
Mastrorillo, M., R. Licker, P. Bohra-Mishra, G. Fagiolo, L. D. Estes, and Oppenheimer, M. (2016), The Influence of Climate Variability on Internal Migration Flows in South Africa, Global Environmental Change, 39: 155-169.

Maurel, M. and Tuccio, M. (2016). Climate instability, urbanisation and international migration. The Journal of Development Studies, 52(5): 735-752.

Maystadt, J.-F. and Ecker, 0. (2014). Extreme weather and civil war: does drought fuel conflict in Somalia through livestock price shocks? American Journal of Agricultural Economics, 96(4): 1157-1182.

Mbaye, L. (2017). Climate change, natural disasters, and migration. IZA World of Labor.

McLeman, R. and Smit, B. (2006). Migration as an adaptation to climate change. Climatic Change, 76(1-2): 31-53.

Mendelsohn, R., Nordhaus, W. D., and Shaw, D. (1994). The impact of global warming on agriculture: a Ricardian analysis. American Economic Review, 753-771.

Mueller, V., Gray, C., and Kosec, K. (2014). Heat stress increases long-term human migration in rural Pakistan. Nature Climate Change, 4(3): 182-185.

Naudé, W. (2010). The Determinants of Migration from Sub-Saharan African Countries, Journal of African Economies, 19: 330-356.

Newell, R.G., Prest, B.C., and Sexton, S.E. (2018). The GDP-temperature relationship: implications for climate change damages. Resources for the future RFF Working Paper N. 1817.

Olper, A., Fałkowski, J., and Swinnen, J. (2014). Political reforms and public policy: evidence from agricultural and food policies. World Bank Economic Review, 28(1): 21-47.

Olper, A., Maugeri, M. and Raimondi, V. (2019). Temperature shocks and economic outcomes: An application of panel data econometrics to Italian provinces. Paper presented at the 8th AIEAA Conference, 13-14 June 2019, Pistoia, Italy.

Özden, Ç., Parsons, C. R., Schiff, M., and Walmsley, T. L. (2011). Where on earth is everybody? The evolution of global bilateral migration 1960-2000. The World Bank Economic Review, 25(1): 12-56.

Rosenzweig, M. R. and Stark, O. (1989). Consumption Smoothing, Migration, and Marriage: Evidence from Rural India, Journal of Political Economy, 97: 905-926.

Roy, A. D. (1951). Some thoughts on the distribution of earnings. Oxford Economic Papers, 3(2): 135-146. 
Schlenker, W., Hanemann, W. M., and Fisher, A. C. (2006). The impact of global warming on US agriculture: an econometric analysis of optimal growing conditions. Review of Economics and Statistics, 88(1): 113-125.

Schlenker, W. and Roberts, M. J. (2009). Nonlinear temperature effects indicate severe damages to u.s. crop yields under climate change. Proceedings of the National Academy of Sciences, 106(37): 15594-15598.

Stark, O. and Bloom, D. (1985). The New Economics of Labor Migration. American Economic Review, 75(2): 173-78.

Stock, J. and Yogo, M. (2005). Testing for Weak Instruments in Linear IV Regression. Cambridge University Press, New York.

Stock, J., Yogo, M., and Wright, J. (2002). A survey of weak instruments and weak identification in generalized method of moments. Journal of Business and Economic Statistics, 20: 518 - 529.

Todaro, M. P. (1969). A model for labor migration and urban unemployment in less developed countries. American Economic Review, 59(1): 138-48. 


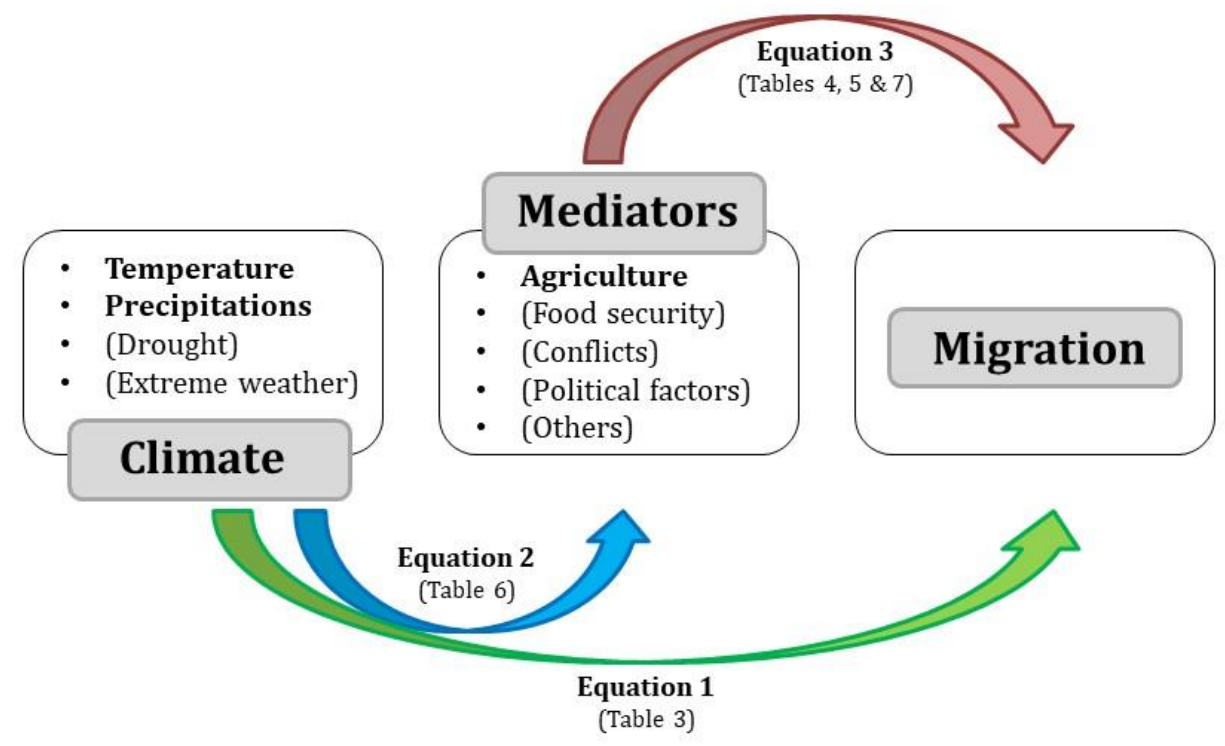

Fig. 1. Conceptual model of climate, agriculture and migration. The figure shows the "direct" reducedform relationship between climate and migration (green arrow). This obscures the mediating role of agriculture and the fact that climate affects migration "indirectly" through agriculture, so that the effect is decomposed into the impact of climate on agriculture (blue arrow) and of agriculture on migration (red arrow). The boxes sow the different indicators of climate, on the one hand, and the other factors affecting migration, which it is important to control for in order to correctly isolate the role of agriculture. 

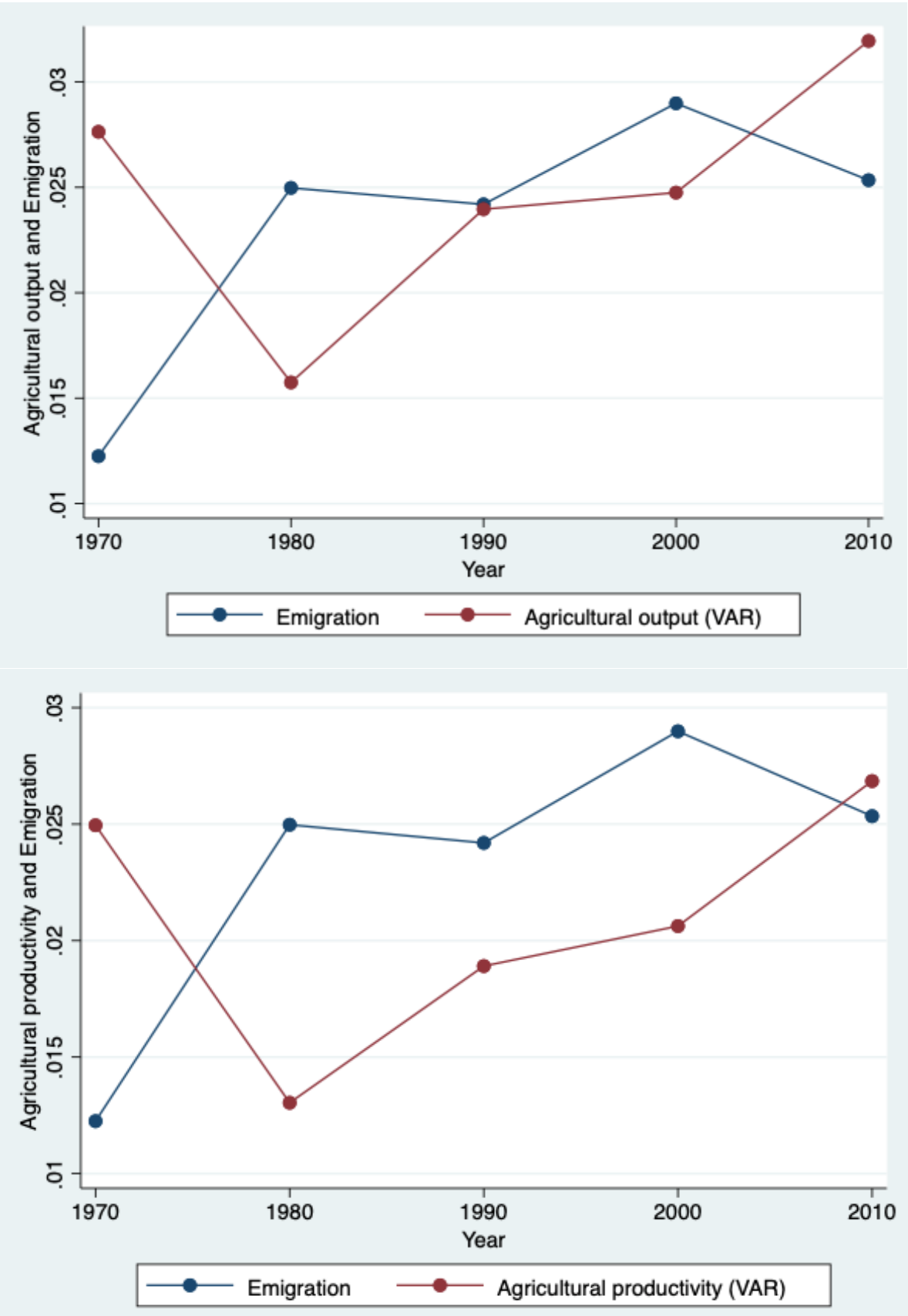

Fig. 2. Emigration and agricultural output/productivity for Poor countries. It is shown the decennial mean variation in migration rate and agricultural output and agricultural productivity in poor countries (Table 1 details the list of countries that belong to the poor group). Source: authors' calculations based on data Özden et al. (2011), World Bank and FAOSTAT. 

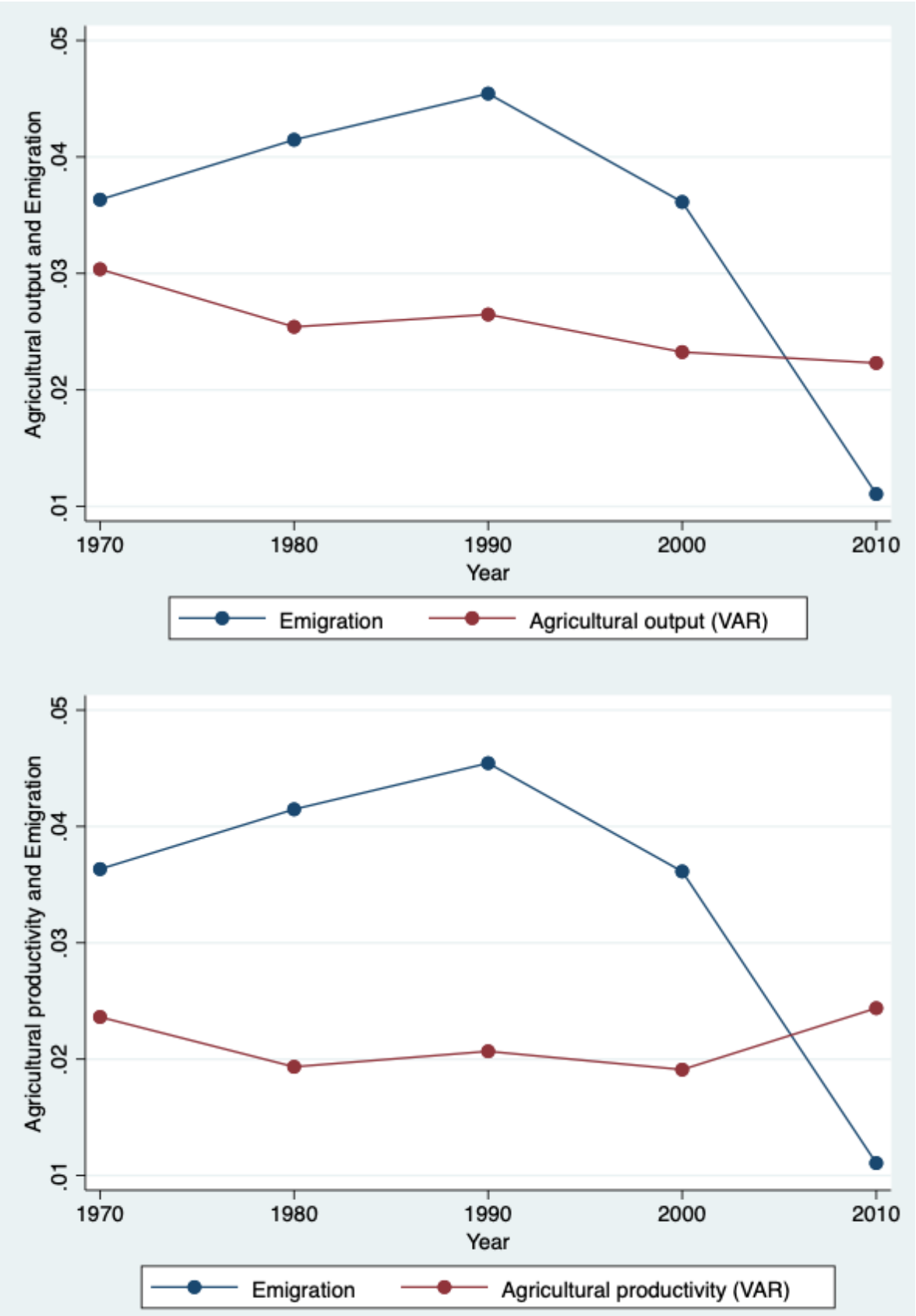

Fig. 3. Emigration and agricultural output/productivity for Middle-Poor countries. It is shown the decennial mean variation in migration rate and agricultural output and agricultural productivity in middle-poor countries (Table 1 details the list of countries that belong to the poor group). Source: authors' calculations based on data Özden et al. (2011), World Bank and FAOSTAT. 


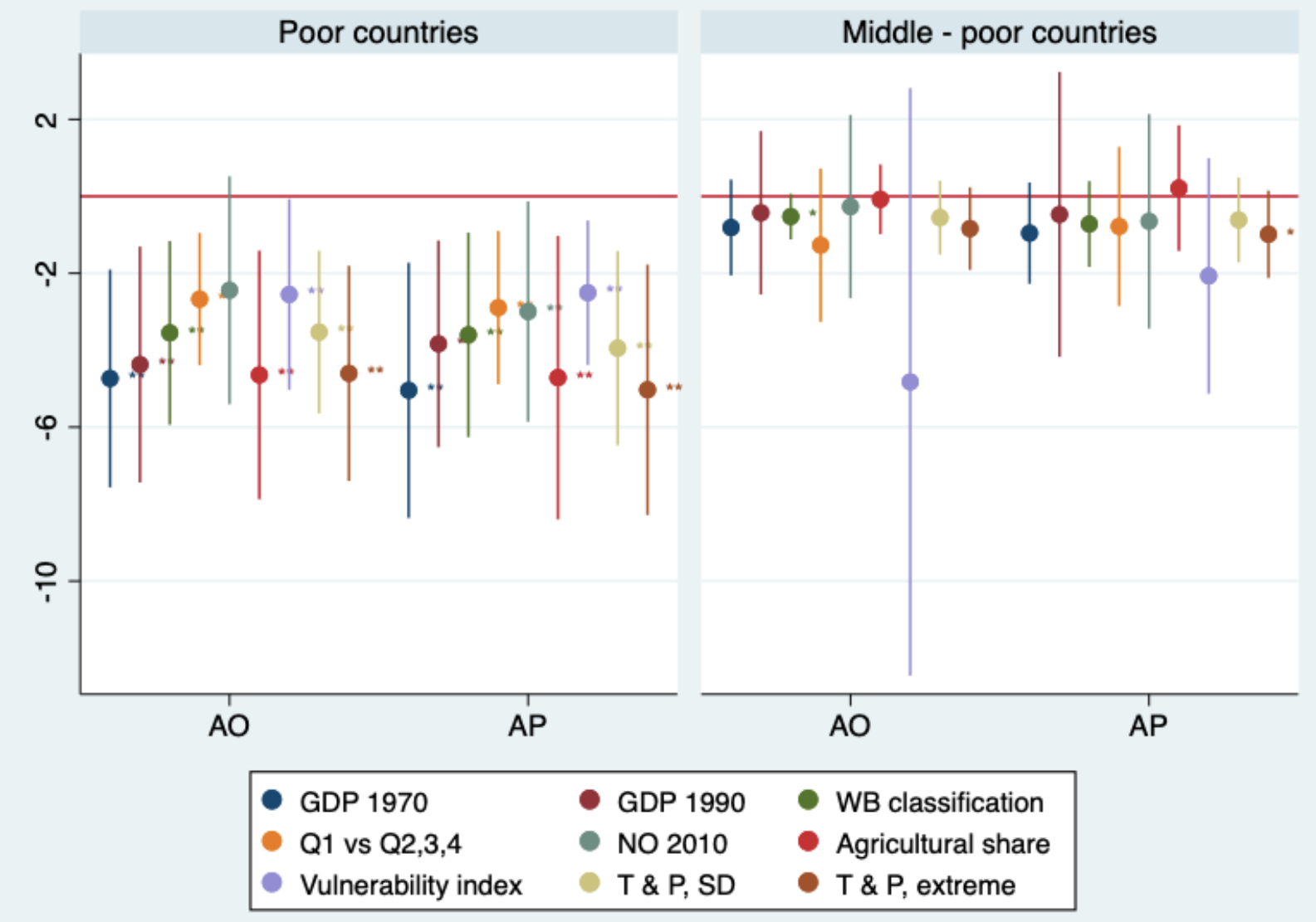

Fig. 4. Robustness checks. The figure reports estimated value of coefficient $\beta$ of the 2SLS migrationagriculture equation (3) in the paper. Coefficients are shown as colored dots together with their significance level and 95\% confidence interval (colored bar). We use both agricultural output (AO) and agricultural productivity (AP) as proxies for agricultural outcomes. The first blue dots starting from the left represent our baseline estimates (GDP 1970), reproducing the 2SLS coefficients of Table 5, columns 3 to 6 , respectively. The other colored dots correspond to the estimation of the same equation (3) under the following criteria: Using the median per capita GDP in 1990 (red dot); Using the World Bank income classification of 1990 (green dot); Using the quartiles of the 1970 income distribution, with Q1 countries as poor, and those of Q2+Q3+Q4 classified as middle-poor (orange dot); Excluding the year 2010 from the sample (light green dot); Using the median value of the share of agriculture in total GDP (light red dot); Using the vulnerability of the agricultural sector to split the sample (violet dot); Adding the decadal standard deviation (SD) of weather variables within the instruments set (sand color dot); Adding extreme temperature and precipitations within the instruments set (brown dot). See the discussion in Section 7.1 in the main text. The regression results for these additional cases are fully presented in the Appendix to the paper. 
Table 1

List of countries of our sample and classification between poor and middle-poor income countries.

\begin{tabular}{|c|c|c|c|c|c|}
\hline \multirow[t]{2}{*}{ Country } & \multicolumn{2}{|c|}{ Category } & \multirow[t]{2}{*}{ Country } & \multicolumn{2}{|c|}{ Category } \\
\hline & Poor & $\begin{array}{l}\text { Middle- } \\
\text { Poor }\end{array}$ & & Poor & $\begin{array}{l}\text { Middle- } \\
\text { Poor }\end{array}$ \\
\hline Afghanistan & $\mathrm{P}$ & & Liberia & $\mathrm{P}$ & \\
\hline Angola & & M-P & Libya & & M-P \\
\hline Albania & $\mathrm{P}$ & & Sri Lanka & $\mathrm{P}$ & \\
\hline United Arab Emirates & & M-P & Lesotho & $\mathrm{P}$ & \\
\hline Argentina & & M-P & Morocco & & M-P \\
\hline Burundi & $\mathrm{P}$ & & Madagascar & $\mathrm{P}$ & \\
\hline Benin & $\mathrm{P}$ & & Mali & $\mathrm{P}$ & \\
\hline Burkina Faso & $\mathrm{P}$ & & Mongolia & $\mathrm{P}$ & \\
\hline Bangladesh & $\mathrm{P}$ & & Mozambique & $\mathrm{P}$ & \\
\hline Bulgaria & $\mathrm{P}$ & & Mauritania & $\mathrm{P}$ & \\
\hline Bahamas & & M-P & Mauritius & & M-P \\
\hline Belize & & $\mathrm{M}-\mathrm{P}$ & Malawi & $\mathrm{P}$ & \\
\hline Bolivia & & M-P & Malaysia & & M-P \\
\hline Brazil & & M-P & Namibia & & M-P \\
\hline Bhutan & $\mathrm{P}$ & & Niger & $\mathrm{P}$ & \\
\hline Botswana & $\mathrm{P}$ & & Nigeria & $\mathrm{P}$ & \\
\hline Central African Rep. & $\mathrm{P}$ & & Nicaragua & & M-P \\
\hline China & $\mathrm{P}$ & & Nepal & $\mathrm{P}$ & \\
\hline Côte d'Ivoire & $\mathrm{P}$ & & New Zealand & & M-P \\
\hline Cameroon & $\mathrm{P}$ & & Oman & & $\mathrm{M}-\mathrm{P}$ \\
\hline Congo & $\mathrm{P}$ & & Pakistan & $\mathrm{P}$ & \\
\hline Colombia & & M-P & Panama & & M-P \\
\hline Comoros & $\mathrm{P}$ & & Peru & & M-P \\
\hline Cabo Verde & $\mathrm{P}$ & & Philippines & & $\mathrm{M}-\mathrm{P}$ \\
\hline Costa Rica & & M-P & Papua New Guinea & $\mathrm{P}$ & \\
\hline Cuba & & $\mathrm{M}-\mathrm{P}$ & Paraguay & & M-P \\
\hline Cyprus & & M-P & Rwanda & $\mathrm{P}$ & \\
\hline Djibouti & & M-P & Saudi Arabia & & M-P \\
\hline Dominican Republic & & M-P & Sudan & $\mathrm{P}$ & \\
\hline Algeria & & M-P & Senegal & $\mathrm{P}$ & \\
\hline Ecuador & & $\mathrm{M}-\mathrm{P}$ & Solomon Islands & $\mathrm{P}$ & \\
\hline Egypt & $\mathrm{P}$ & & Sierra Leone & $\mathrm{P}$ & \\
\hline Ethiopia & $\mathrm{P}$ & & El Salvador & & M-P \\
\hline Fiji & & $\mathrm{M}-\mathrm{P}$ & Somalia & $\mathrm{P}$ & \\
\hline
\end{tabular}




\begin{tabular}{|c|c|c|c|c|c|}
\hline Gabon & & $\mathrm{M}-\mathrm{P}$ & Sao Tome and P.pe & & M-P \\
\hline Ghana & $\mathrm{P}$ & & Suriname & & M-P \\
\hline Guinea & & $\mathrm{M}-\mathrm{P}$ & Eswatini & $\mathrm{P}$ & \\
\hline Gambia & $\mathrm{P}$ & & Syrian Arab Rep. & $\mathrm{P}$ & \\
\hline Guinea-Bissau & $\mathrm{P}$ & & Chad & $\mathrm{P}$ & \\
\hline Equatorial Guinea & $\mathrm{P}$ & & Togo & $\mathrm{P}$ & \\
\hline Guatemala & & $\mathrm{M}-\mathrm{P}$ & Thailand & $\mathrm{P}$ & \\
\hline Guyana & $\mathrm{P}$ & & Trinidad \& Tobago & & $\mathrm{M}-\mathrm{P}$ \\
\hline Honduras & $\mathrm{P}$ & & Tunisia & & M-P \\
\hline Haiti & $\mathrm{P}$ & & Tanzania & $\mathrm{P}$ & \\
\hline Indonesia & $\mathrm{P}$ & & Uganda & $\mathrm{P}$ & \\
\hline India & $\mathrm{P}$ & & Uruguay & & $\mathrm{M}-\mathrm{P}$ \\
\hline Iran & & $\mathrm{M}-\mathrm{P}$ & $\begin{array}{l}\text { Saint Vincent and the } \\
\text { Grenadines }\end{array}$ & $\mathrm{P}$ & \\
\hline Iraq & & $\mathrm{M}-\mathrm{P}$ & Venezuela & & $\mathrm{M}-\mathrm{P}$ \\
\hline Jamaica & & M-P & Viet Nam & $\mathrm{P}$ & \\
\hline Jordan & & M-P & Vanuatu & & $\mathrm{M}-\mathrm{P}$ \\
\hline Kenya & $\mathrm{P}$ & & Samoa & & M-P \\
\hline Cambodia & $\mathrm{P}$ & & South Africa & & M-P \\
\hline Lao People's Dem. Rep. & $\mathrm{P}$ & & Zambia & & $\mathrm{M}-\mathrm{P}$ \\
\hline Lebanon & & M-P & Zimbabwe & $\mathrm{P}$ & \\
\hline
\end{tabular}

Classification of countries according to the criterion used for our baseline estimation results, the level of GDP in 1970. See Section 5 of the paper. The total number of countries is 108, of which 60 Poor and 48 Middle-Poor countries. 
Table 2

Summary statistics.

\begin{tabular}{|c|c|c|c|c|}
\hline Variables & Mean & SD & Min & Max \\
\hline All countries & & & & \\
\hline Emigration & 2.924 & 4.232 & 0.016 & 35.068 \\
\hline Temperature & 22.731 & 4.596 & -1.322 & 28.998 \\
\hline Precipitations & 12.895 & 7.594 & 0.206 & 42.019 \\
\hline Agricultural output & 8647.268 & 37054.560 & 13.150 & 536769.600 \\
\hline Agricultural productivity & 47.402 & 63.752 & 0.406 & 582.031 \\
\hline GDP per capita & 2956.351 & 4098.896 & 136.269 & 40009.610 \\
\hline Wars & 1.224 & 2.753 & 0 & 10 \\
\hline Democracy & 46.835 & 49.952 & 0 & 100 \\
\hline Life expectancy & 57.765 & 10.566 & 27.220 & 78.150 \\
\hline Agricultural share & 23.060 & 13.591 & 1.181 & 66.582 \\
\hline FAO index & 19.476 & 24.477 & 0 & 100 \\
\hline Network index & 48.734 & 50.037 & 0 & 100 \\
\hline Diversification index & 72.865 & 9.972 & 47.798 & 89.091 \\
\hline Extreme temperature & 0.251 & 0.506 & 0 & 2 \\
\hline Extreme precipitations & 0.241 & 0.549 & 0 & 3 \\
\hline Poor countries & & & & \\
\hline Emigration & 2.467 & 3.704 & 0.016 & 27.674 \\
\hline Temperature & 23.094 & 5.155 & -1.322 & 28.998 \\
\hline Precipitations & 12.396 & 6.646 & 0.257 & 29.371 \\
\hline Agricultural output & 11332.970 & 47340.500 & 18.402 & 536769.600 \\
\hline Agricultural productivity & 43.445 & 66.339 & 0.608 & 582.031 \\
\hline GDP per capita & 1298.255 & 1169.739 & 136.269 & 6444.710 \\
\hline Wars & 1.202 & 2.620 & 0 & 10 \\
\hline Democracy & 43.382 & 49.651 & 0 & 100 \\
\hline Life expectancy & 53.421 & 9.859 & 27.220 & 76.061 \\
\hline Agricultural share & 30.780 & 12.243 & 1.181 & 66.582 \\
\hline FAO index & 15.701 & 22.172 & 0 & 100 \\
\hline Network index & 36.765 & 48.305 & 0 & 100 \\
\hline Diversification index & 73.739 & 9.989 & 47.798 & 89.091 \\
\hline Extreme temperature & 0.265 & 0.526 & 0 & 2 \\
\hline Extreme precipitations & 0.206 & 0.565 & 0 & 3 \\
\hline
\end{tabular}




\begin{tabular}{|l|c|c|c|c|} 
Emigration & 3.538 & 4.795 & 0.090 & 35.068 \\
Temperature & 22.243 & 3.669 & 13.205 & 28.461 \\
Precipitations & 13.567 & 8.682 & 0.206 & 42.019 \\
Agricultural output & 5030.881 & 13658.930 & 13.150 & 140549.500 \\
Agricultural productivity & 52.731 & 59.841 & 0.406 & 290.060 \\
GDP per capita & 5085.386 & 5350.890 & 692.091 & 40009.610 \\
Wars & 1.252 & 2.929 & 0 & 10 \\
Democracy & 51.485 & 50.102 & 0 & 100 \\
Life expectancy & 63.614 & 8.471 & 38.870 & 78.150 \\
Agricultural share & 12.508 & 6.287 & 1.255 & 23.973 \\
FAO index & 24.020 & 26.340 & 0.800 & 100 \\
Network index & 64.851 & 47.862 & 0 & 100 \\
Diversification index & 71.677 & 9.850 & 50.814 & 88.413 \\
Extreme temperature & 0.233 & 0.479 & 0 & 2 \\
Extreme precipitations & 0.287 & 0.525 & 0 & 3 \\
\hline
\end{tabular}

Summary statistics for the variables used in the empirical analysis of the paper, both for all countries in the sample and separately for the group of poor and middle-income countries. The variables are defined in Section 5 of the main text where the source of data is also indicated. 
Table 3

Migration and climate: reduced-form estimation results.

\begin{tabular}{|c|c|c|c|}
\hline & All countries & $\begin{array}{c}\text { Poor } \\
\text { countries }\end{array}$ & $\begin{array}{l}\text { Middle-poor } \\
\text { countries }\end{array}$ \\
\hline & 1 & 2 & 3 \\
\hline \multicolumn{4}{|c|}{ Dependent variable: log of emigration rate } \\
\hline Temperature & $\begin{array}{c}1.765^{* *} \\
(2.36)\end{array}$ & $\begin{array}{c}2.479 * * * \\
(2.87)\end{array}$ & $\begin{array}{l}-0.479 \\
(-0.45)\end{array}$ \\
\hline Temperature $^{2}$ & $\begin{array}{c}-0.039 * * \\
(-2.46)\end{array}$ & $\begin{array}{c}-0.055^{* * *} \\
(-3.47)\end{array}$ & $\begin{array}{l}0.014 \\
(0.57)\end{array}$ \\
\hline Precipitations & $\begin{array}{l}-0.010 \\
(-0.15)\end{array}$ & $\begin{array}{l}0.050 \\
(0.66)\end{array}$ & $\begin{array}{l}-0.063 \\
(-0.57)\end{array}$ \\
\hline Precipitations $^{2}$ & $\begin{array}{l}-0.001 \\
(-0.32)\end{array}$ & $\begin{array}{l}-0.003 \\
(-1.27)\end{array}$ & $\begin{array}{l}0.001 \\
(0.44)\end{array}$ \\
\hline $\mathrm{R}^{2}$ & 0.733 & 0.713 & 0.766 \\
\hline No. observations & 474 & 272 & 202 \\
\hline
\end{tabular}

Estimation results from reduced-form fixed effects regressions as described in equation (1) of the main text and discussed in Section 6.1. Robust t-statistics in parentheses. Asterisks refer to the following cases: ${ }^{*} p<0.10,{ }^{* *} p<0.05,{ }^{* * *} p<0.01$. The sample split between country groups is made on the basis of 1970 per capita GDP. All specifications include 10-year and country fixed effects. 
Table 4

Migration and agriculture climate: estimation results from OLS fixed effects regressions.

\begin{tabular}{|c|c|c|c|c|c|c|}
\hline & \multicolumn{2}{|c|}{ All countries } & \multicolumn{2}{|c|}{ Poor countries } & \multicolumn{2}{|c|}{ Middle-poor countries } \\
\hline & 1 & 2 & 3 & 4 & 5 & 6 \\
\hline \multicolumn{7}{|c|}{ Dependent variable: log of emigration rate } \\
\hline Agricultural output & $\begin{array}{c}-0.476^{* * *} \\
(-2.64)\end{array}$ & & $\begin{array}{c}-0.797^{* * *} \\
(-2.69)\end{array}$ & & $\begin{array}{l}-0.224 \\
(-0.95)\end{array}$ & \\
\hline $\begin{array}{l}\text { Agricultural } \\
\text { productivity }\end{array}$ & & $\begin{array}{c}-0.560 * * * \\
(-2.71)\end{array}$ & & $\begin{array}{c}-0.658 * * \\
(-1.98)\end{array}$ & & $\begin{array}{c}-0.568^{* *} \\
(-2.47)\end{array}$ \\
\hline GDP per capita & $\begin{array}{l}-0.079 \\
(-0.73)\end{array}$ & $\begin{array}{l}-0.066 \\
(-0.61)\end{array}$ & $\begin{array}{l}-0.165 \\
(-1.03)\end{array}$ & $\begin{array}{l}-0.170 \\
(-1.05)\end{array}$ & $\begin{array}{l}0.078 \\
(0.62)\end{array}$ & $\begin{array}{l}0.120 \\
(0.95)\end{array}$ \\
\hline Wars & $\begin{array}{l}0.018 \\
(1.10)\end{array}$ & $\begin{array}{l}0.020 \\
(1.24)\end{array}$ & $\begin{array}{l}0.002 \\
(0.10)\end{array}$ & $\begin{array}{l}0.007 \\
(0.27)\end{array}$ & $\begin{array}{l}0.020 \\
(0.89)\end{array}$ & $\begin{array}{l}0.022 \\
(1.03)\end{array}$ \\
\hline Democracy & $\begin{array}{l}0.120 \\
(1.02)\end{array}$ & $\begin{array}{l}0.118 \\
(1.01)\end{array}$ & $\begin{array}{l}0.073 \\
(0.50)\end{array}$ & $\begin{array}{l}0.098 \\
(0.67)\end{array}$ & $\begin{array}{l}0.281 \\
(1.51)\end{array}$ & $\begin{array}{l}0.238 \\
(1.28)\end{array}$ \\
\hline Life expectancy & $\begin{array}{l}-0.013 \\
(-0.88)\end{array}$ & $\begin{array}{l}-0.014 \\
(-0.97)\end{array}$ & $\begin{array}{l}-0.021 \\
(-1.22)\end{array}$ & $\begin{array}{l}-0.027 \\
(-1.56)\end{array}$ & $\begin{array}{l}0.009 \\
(0.41)\end{array}$ & $\begin{array}{l}0.016 \\
(0.78)\end{array}$ \\
\hline $\begin{array}{l}\mathrm{R}^{2} \\
\text { No. observations }\end{array}$ & $\begin{array}{c}0.735 \\
474\end{array}$ & $\begin{array}{c}0.736 \\
474 \\
\end{array}$ & $\begin{array}{c}0.714 \\
272 \\
\end{array}$ & $\begin{array}{c}0.708 \\
272\end{array}$ & $\begin{array}{c}0.769 \\
202 \\
\end{array}$ & $\begin{array}{c}0.776 \\
202\end{array}$ \\
\hline
\end{tabular}

Estimation results from OLS fixed effects regressions as discussed in Section 6.1 of the main text. We use both agricultural output and agricultural productivity as proxies for agricultural outcomes. Robust tstatistics in parentheses. Asterisks refer to the following cases: ${ }^{*} \mathrm{p}<0.10,{ }^{* *} \mathrm{p}<0.05,{ }^{* * *} \mathrm{p}<0.01$. The sample split between country groups is made on the basis of 1970 per capita GDP. All specifications include 10-year and country fixed effects. 
Table 5

Migration and agriculture: second stage estimation results.

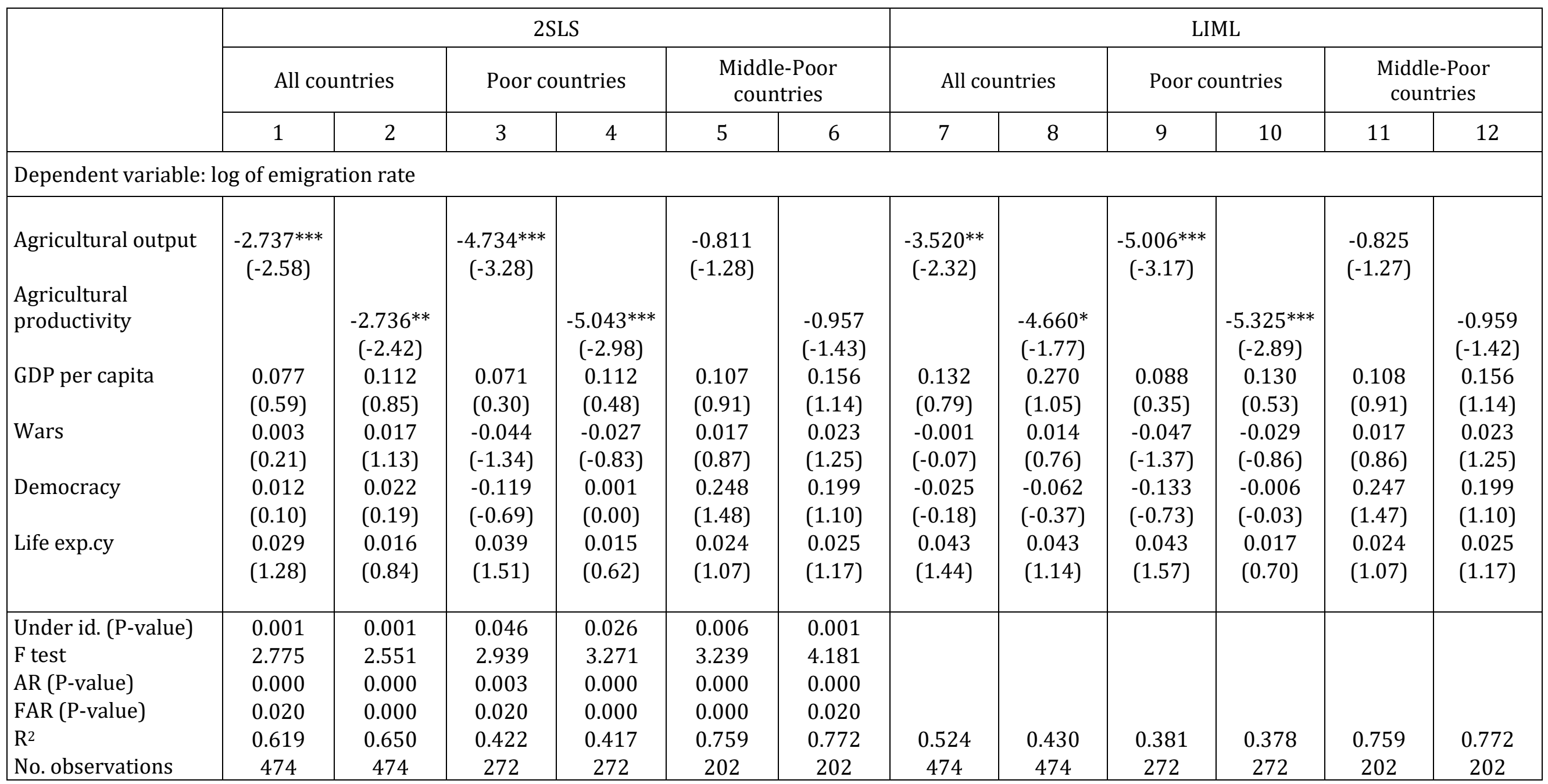


Estimated coefficients of the Migration and agriculture relationship given by equation (3) in the main text (second stage regression). We show the results from both fixed effects 2SLS and LIML estimation methods. We use both agricultural output and agricultural productivity as proxies for agricultural outcomes. Robust $t$ statistics in parentheses. Asterisks refer to the following cases: ${ }^{*} \mathrm{p}<0.10,{ }^{* *} \mathrm{p}<0.05,{ }^{* * *} \mathrm{p}<0.01$. The sample split between country groups is made on the basis of 1970 per capita GDP. All specifications include 10-year and country fixed effects. 


\section{Table 6}

Agriculture and climate: first stage estimation results.

\begin{tabular}{|c|c|c|c|c|c|c|}
\hline & \multicolumn{2}{|c|}{ All countries } & \multicolumn{2}{|c|}{ Poor countries } & \multicolumn{2}{|c|}{ Middle-Poor countries } \\
\hline & 1 & 2 & 3 & 4 & 5 & 6 \\
\hline Dependent variables: & $\mathrm{AO}$ & $\mathrm{AP}$ & $\mathrm{AO}$ & $\mathrm{AP}$ & $\mathrm{AO}$ & $\mathrm{AP}$ \\
\hline Temperature & $\begin{array}{c}-0.335^{* *} \\
(-2.01)\end{array}$ & $\begin{array}{l}-0.172 \\
(-1.16)\end{array}$ & $\begin{array}{c}-0.535^{* * *} \\
(-2.83)\end{array}$ & $\begin{array}{l}-0.410^{* *} \\
(-2.58)\end{array}$ & $\begin{array}{l}0.277 \\
(0.94)\end{array}$ & $\begin{array}{c}0.520^{* *} \\
(2.00)\end{array}$ \\
\hline Temperature $^{2}$ & $\begin{array}{l}0.006 \\
(1.51)\end{array}$ & $\begin{array}{l}0.003 \\
(0.77)\end{array}$ & $\begin{array}{c}0.011^{* * *} \\
(2.71)\end{array}$ & $\begin{array}{c}0.008^{* *} \\
(2.43)\end{array}$ & $\begin{array}{l}-0.009 \\
(-1.28)\end{array}$ & $\begin{array}{c}-0.014^{* *} \\
(-2.22)\end{array}$ \\
\hline Precipitations & $\begin{array}{l}0.010 \\
(0.46)\end{array}$ & $\begin{array}{l}0.011 \\
(0.54)\end{array}$ & $\begin{array}{l}0.000 \\
(0.02)\end{array}$ & $\begin{array}{l}-0.014 \\
(-0.90)\end{array}$ & $\begin{array}{l}0.055 \\
(1.43)\end{array}$ & $\begin{array}{l}0.064 \\
(1.57)\end{array}$ \\
\hline Precipitations $^{2}$ & $\begin{array}{l}0.000 \\
(0.40)\end{array}$ & $\begin{array}{l}0.000 \\
(0.29)\end{array}$ & $\begin{array}{l}0.000 \\
(0.37)\end{array}$ & $\begin{array}{l}0.001 \\
(1.53)\end{array}$ & $\begin{array}{l}-0.001 \\
(-0.70)\end{array}$ & $\begin{array}{l}-0.001 \\
(-1.03)\end{array}$ \\
\hline GDP per capita & $\begin{array}{c}0.072^{* *} \\
(1.97)\end{array}$ & $\begin{array}{c}0.084^{* * *} \\
(2.66)\end{array}$ & $\begin{array}{l}0.060 \\
(1.10)\end{array}$ & $\begin{array}{l}0.063 \\
(1.44)\end{array}$ & $\begin{array}{l}0.042 \\
(0.73)\end{array}$ & $\begin{array}{l}0.081 \\
(1.49)\end{array}$ \\
\hline Wars & $\begin{array}{l}-0.005 \\
(-1.35)\end{array}$ & $\begin{array}{l}-0.001 \\
(-0.24)\end{array}$ & $\begin{array}{l}-0.009^{*} \\
(-1.85)\end{array}$ & $\begin{array}{l}-0.006 \\
(-1.09)\end{array}$ & $\begin{array}{l}-0.005 \\
(-0.68)\end{array}$ & $\begin{array}{l}0.002 \\
(0.33)\end{array}$ \\
\hline Democracy & $\begin{array}{l}-0.049^{*} \\
(-1.67)\end{array}$ & $\begin{array}{l}-0.045 \\
(-1.64)\end{array}$ & $\begin{array}{l}-0.052 \\
(-1.57)\end{array}$ & $\begin{array}{l}-0.023 \\
(-0.75)\end{array}$ & $\begin{array}{l}-0.047 \\
(-0.76)\end{array}$ & $\begin{array}{l}-0.089 \\
(-1.54)\end{array}$ \\
\hline Life expectancy & $\begin{array}{c}0.019 * * * \\
(5.91)\end{array}$ & $\begin{array}{c}0.014^{* * *} \\
(4.52)\end{array}$ & $\begin{array}{c}0.015^{* * *} \\
(4.18)\end{array}$ & $\begin{array}{c}0.010^{* * *} \\
(2.61)\end{array}$ & $\begin{array}{c}0.027^{* * *} \\
(3.56)\end{array}$ & $\begin{array}{c}0.022^{* * *} \\
(3.45)\end{array}$ \\
\hline $\begin{array}{l}\mathrm{R}^{2} \\
\text { No. observations }\end{array}$ & $\begin{array}{c}0.991 \\
474 \\
\end{array}$ & $\begin{array}{c}0.987 \\
474\end{array}$ & $\begin{array}{c}0.992 \\
272\end{array}$ & $\begin{array}{c}0.989 \\
272\end{array}$ & $\begin{array}{c}0.989 \\
202\end{array}$ & $\begin{array}{c}0.985 \\
202\end{array}$ \\
\hline
\end{tabular}

Estimated coefficients of the Agriculture and climate relationship given by equation (2) in the main text (first stage regression). Robust t-statistics in parentheses. We use both agricultural output (AO) and agricultural productivity (AP) as proxies for agricultural outcomes. Asterisks refer to the following cases: ${ }^{*} \mathrm{p}<0.10,{ }^{* *} \mathrm{p}<0.05,{ }^{* * *} \mathrm{p}<0.01$. The sample split between country groups is made on the basis of 1970 per capita GDP. All specifications include 10-year and country fixed effects. 


\section{Table 7}

Migration and agriculture relationship: estimation results with instrumented controls.

\begin{tabular}{|c|c|c|c|c|c|c|c|c|c|c|c|c|}
\hline & $\begin{array}{c}\text { All } \\
\text { countries }\end{array}$ & $\begin{array}{c}\text { Poor } \\
\text { countries }\end{array}$ & $\begin{array}{l}\text { Middle- } \\
\text { Poor } \\
\text { countries }\end{array}$ & $\begin{array}{c}\text { All } \\
\text { countries }\end{array}$ & $\begin{array}{c}\text { Poor } \\
\text { countries }\end{array}$ & $\begin{array}{l}\text { Middle- } \\
\text { Poor } \\
\text { countries }\end{array}$ & $\begin{array}{c}\text { All } \\
\text { countries }\end{array}$ & $\begin{array}{c}\text { Poor } \\
\text { countries }\end{array}$ & $\begin{array}{l}\text { Middle- } \\
\text { Poor } \\
\text { countries }\end{array}$ & $\begin{array}{c}\text { All } \\
\text { countries }\end{array}$ & $\begin{array}{c}\text { Poor } \\
\text { countries }\end{array}$ & $\begin{array}{l}\text { Middle- } \\
\text { Poor } \\
\text { countries }\end{array}$ \\
\hline & 1 & 2 & 3 & 4 & 5 & 6 & 7 & 8 & 9 & 10 & 11 & 12 \\
\hline & \multicolumn{3}{|c|}{$\begin{array}{l}\text { Instrumented explanatory } \\
\text { variable: GDP per capita }\end{array}$} & \multicolumn{3}{|c|}{$\begin{array}{l}\text { Instrumented explanatory } \\
\text { variable: Wars }\end{array}$} & \multicolumn{3}{|c|}{$\begin{array}{l}\text { Instrumented explanatory } \\
\text { variable: Democracy }\end{array}$} & \multicolumn{3}{|c|}{$\begin{array}{l}\text { Instrumented explanatory } \\
\text { variable: Life expectancy }\end{array}$} \\
\hline $\begin{array}{l}\text { Agricultural } \\
\text { productivity }\end{array}$ & $\begin{array}{c}-1.169^{*} \\
(-1.85)\end{array}$ & $\begin{array}{l}-1.053^{*} \\
(-1.67)\end{array}$ & $\begin{array}{l}-0.482 \\
(-1.51)\end{array}$ & $\begin{array}{l}-0.440^{* *} \\
(-2.01)\end{array}$ & $\begin{array}{l}0.0004 \\
(0.00)\end{array}$ & $\begin{array}{c}-0.547^{* * *} \\
(-2.58)\end{array}$ & $\begin{array}{c}-0.685^{* * *} \\
(-2.61)\end{array}$ & $\begin{array}{c}-0.758^{* *} \\
(-2.32)\end{array}$ & $\begin{array}{l}-0.534 \\
(-1.11)\end{array}$ & $\begin{array}{c}-0.962^{* * *} \\
(-2.74)\end{array}$ & $\begin{array}{c}-1.112^{* * *} \\
(-2.62)\end{array}$ & $\begin{array}{c}-0.617^{* *} \\
(-2.02)\end{array}$ \\
\hline GDP p.c. & $\begin{array}{l}1.813 \\
(1.12)\end{array}$ & $\begin{array}{l}1.069 \\
(0.70)\end{array}$ & $\begin{array}{l}-0.172 \\
(-0.25)\end{array}$ & $\begin{array}{l}0.012 \\
(0.09)\end{array}$ & $\begin{array}{l}0.165 \\
(0.54)\end{array}$ & $\begin{array}{l}0.110 \\
(1.03)\end{array}$ & $\begin{array}{l}-0.147 \\
(-1.22)\end{array}$ & $\begin{array}{l}-0.198 \\
(-1.30)\end{array}$ & $\begin{array}{l}0.132 \\
(0.65)\end{array}$ & $\begin{array}{l}-0.172 \\
(-1.30)\end{array}$ & $\begin{array}{l}-0.206 \\
(-1.25)\end{array}$ & $\begin{array}{l}0.105 \\
(0.76)\end{array}$ \\
\hline Wars & $\begin{array}{l}0.041 \\
(1.47)\end{array}$ & $\begin{array}{l}0.031 \\
(0.79)\end{array}$ & $\begin{array}{l}0.021 \\
(1.15)\end{array}$ & $\begin{array}{l}0.422 \\
(1.38)\end{array}$ & $\begin{array}{l}0.826 \\
(1.39)\end{array}$ & $\begin{array}{l}-0.064 \\
(-0.22)\end{array}$ & $\begin{array}{l}0.027 \\
(1.47)\end{array}$ & $\begin{array}{l}0.012 \\
(0.49)\end{array}$ & $\begin{array}{l}0.022 \\
(1.13)\end{array}$ & $\begin{array}{l}0.040^{*} \\
(1.74)\end{array}$ & $\begin{array}{l}0.043 \\
(1.17)\end{array}$ & $\begin{array}{l}0.023 \\
(1.22)\end{array}$ \\
\hline Democracy & $\begin{array}{l}0.241 \\
(1.42)\end{array}$ & $\begin{array}{l}0.136 \\
(0.89)\end{array}$ & $\begin{array}{l}0.203 \\
(1.16)\end{array}$ & $\begin{array}{l}0.033 \\
(0.21)\end{array}$ & $\begin{array}{l}-0.001 \\
(-0.01)\end{array}$ & $\begin{array}{l}0.252 \\
(1.44)\end{array}$ & $\begin{array}{l}-1,025 \\
(-0.97)\end{array}$ & $\begin{array}{l}-0.876 \\
(-0.99)\end{array}$ & $\begin{array}{l}0.458 \\
(0.17)\end{array}$ & $\begin{array}{l}-0.046 \\
(-0.28)\end{array}$ & $\begin{array}{l}-0.125 \\
(-0.62)\end{array}$ & $\begin{array}{l}0.229 \\
(1.36)\end{array}$ \\
\hline Life exp.cy & $\begin{array}{l}-0.033 \\
(-1.42)\end{array}$ & $\begin{array}{c}-0.032^{*} \\
(-1.79)\end{array}$ & $\begin{array}{l}0.022 \\
(1.03)\end{array}$ & $\begin{array}{l}0.015 \\
(0.53)\end{array}$ & $\begin{array}{l}0.038 \\
(0.65)\end{array}$ & $\begin{array}{l}0.014 \\
(0.74)\end{array}$ & $\begin{array}{l}0.006 \\
(0.29)\end{array}$ & $\begin{array}{l}-0.006 \\
(-0.25)\end{array}$ & $\begin{array}{l}0.015 \\
(0.55)\end{array}$ & $\begin{array}{l}0.090 \\
(1.09)\end{array}$ & $\begin{array}{l}0.083 \\
(1.02)\end{array}$ & $\begin{array}{l}0.028 \\
(0.42)\end{array}$ \\
\hline $\begin{array}{c}\mathrm{R}^{2} \\
\text { No. obs. }\end{array}$ & $\begin{array}{c}0.467 \\
504\end{array}$ & $\begin{array}{c}0.593 \\
272\end{array}$ & $\begin{array}{c}0.769 \\
202\end{array}$ & $\begin{array}{c}0.450 \\
504\end{array}$ & $\begin{array}{c}-0.364 \\
272\end{array}$ & $\begin{array}{c}0.759 \\
202\end{array}$ & $\begin{array}{c}0.667 \\
504\end{array}$ & $\begin{array}{c}0.642 \\
272\end{array}$ & $\begin{array}{c}0.774 \\
202\end{array}$ & $\begin{array}{c}0.682 \\
504\end{array}$ & $\begin{array}{c}0.628 \\
272\end{array}$ & $\begin{array}{c}0.775 \\
202 \\
\end{array}$ \\
\hline
\end{tabular}


Estimated coefficients of the Migration and agriculture relationship with instrumented controls. We consider as instrumented explanatory variables the controls we included in equation (3) of the main text and discussed in Section 7.2. In bold characters we report the estimated coefficients and (robust) standard errors corresponding to the instrumented explanatory variable: from columns (1-3) GDP per capita; from columns (4-6) wars; from columns (7-9) Democracy; from columns (10-12) Life expectancy. See the discussion in Section 6.2 of the main text. We use agricultural productivity as proxy for agricultural outcomes. Robust tstatistics in parentheses. Asterisks refer to the following cases: ${ }^{*} p<0.10,{ }^{* *} p<0.05,{ }^{* * *} p<0.01$. The sample split between country groups is made on the basis of 1970 per capita GDP. All specifications include 10-year and country fixed effects. 